\title{
Expression of Transfected Vimentin Genes in Differentiating Murine Erythroleukemia Cells Reveals Divergent cis-Acting Regulation of Avian and Mammalian Vimentin Sequences
}

\author{
JOHN NGAI, V. CRAIG BOND, BARBARA J. WOLD, AND ELIAS LAZARIDES* \\ Division of Biology, California Institute of Technology, Pasadena, California 91125
}

Received 26 June 1987/Accepted 30 July 1987

\begin{abstract}
We studied the expression of transfected chicken and hamster vimentin genes in murine erythroleukemia (MEL) cells. MEL cells normally repress the levels of endogenous mouse vimentin mRNA during inducermediated differentiation, resulting in a subsequent loss of vimentin filaments. Expression of vimentin in differentiating MEL cells reflects the disappearance of vimentin filaments during mammalian erythropoiesis in vivo. In contrast, chicken erythroid cells express high levels of vimentin mRNA and vimentin filaments during terminal differentiation. We demonstrate here that chicken vimentin mRNA levels increase significantly in differentiating transfected MEL cells, whereas similarly transfected hamster vimentin genes are negatively regulated. In conjunction with in vitro nuclear run-on transcription experiments, these results suggest that the difference in vimentin expression in avian and mammalian erythropoiesis is due to a divergence of cis-linked vimentin sequences that are responsible for transcriptional and posttranscriptional regulation of vimentin gene expression. Transfected chicken vimentin genes produce functional vimentin protein and stable vimentin filaments during MEL cell differentiation, further demonstrating that the accumulation of vimentin filaments is determined by the abundance of newly synthesized vimentin.
\end{abstract}

Intermediate filaments represent a family of cytoskeletal structures whose members are expressed in developmentally regulated and tissue-specific patterns in vertebrate cells. Keratins are expressed in epithelial cells and cells of epithelial origin, desmin in smooth and striated muscle, glial fibrillary acidic protein in glial cells, neurofilaments in neuronal cells, and vimentin in a wide variety of both immature and differentiated cell types (reviewed in references 47 and 84). The specificity of intermediate-filament protein expression in developing cell lineages suggests that each intermediate-filament protein type plays an important morphogenetic role in cellular differentiation. An interesting facet of the study of intermediate-filament proteins indeed pertains to their patterns of developmental and tissuespecific regulation. Vimentin expression is both positively and negatively regulated during the differentiation of a variety of cell types. For example, in chicken spinal cord, vimentin is replaced by neurofilament protein during the terminal differentiation of neurons (86). In muscle, astrocytes, and certain retinal neurons, vimentin is coexpressed with the cell type-specific intermediate-filament protein (desmin, glial fibrillary acidic protein, and neurofilament protein, respectively) in the fully differentiated state $(24,33$, $80,86,95)$. Fibroblasts, lens fibers, and avian erythrocytes express vimentin as the major intermediate-filament protein subunit of the mature cell $(8,29,36,77)$.

The generality and diversity of vimentin expression suggest that its regulation is necessarily complex. This complexity is particularly evident from a comparison of avian and mammalian erythropoiesis. The mature avian erythrocyte is a nucleated biconvex ellipsoidally shaped cell. Ultrastructural analyses of avian erythrocytes have revealed a network of intermediate filaments that spans the cytoplasm and appears to anchor the centrally located nucleus $(34,89,92)$. The major subunit protein of these filaments is vimentin (36).

\footnotetext{
* Corresponding author.
}

In contrast, the anucleate, biconcave disk-shaped mammalian erythrocyte contains no intermediate filaments. Studies of human hematopoiesis in vivo have demonstrated that vimentin is expressed early in erythroid differentiation but is lost in the erythroblastic stages (22).

In chicken erythroid cells, vimentin filaments are assembled rapidly and stably from a soluble pool of newly synthesized vimentin $(5,62)$. The efficiency and rapidity of vimentin assembly in vivo suggest that the extent of vimentin filament formation is determined primarily by the amount of vimentin synthesized. We have shown that the expression of vimentin protein during erythropoiesis is determined primarily by mRNA abundance $(10,69)$. In chicken embryonic erythropoiesis, vimentin mRNA is found at low levels in immature, mitotic primitive cells and accumulates to increasingly higher levels during terminal differentiation of the definitive erythroid lineage, apparently underlying similar changes at the protein level (10). During differentiation of murine erythroleukemia (MEL) cells in vitro, vimentin mRNA levels rapidly and extensively decline $(\sim 25$ fold reduction), rendering a concomitant decrease in vimentin synthesis and a subsequent loss of vimentin filaments (69). The striking difference in the changes of vimentin mRNA abundances (and, ultimately, vimentin filaments) during mammalian and avian erythropoiesis presents an opportunity to study not only the factors responsible for the dynamic positive and negative regulation of the vimentin gene but also the basis for the evolutionary divergence of the two erythropoietic programs with regard to vimentin expression.

In the present study, we addressed these issues by examining the behavior of transfected chicken and hamster vimentin genes in differentiating MEL cells. The utility of studying both resident and transfected genes during in vitro differentiation of MEL cells is well established (reviewed in references 13 and 55). We demonstrate that, in MEL cell lines harboring and expressing chicken vimentin genes, 
chicken vimentin mRNA levels either increased 2- to 10-fold or remained constant during dimethyl sulfoxide (DMSO)mediated differentiation, whereas resident mouse vimentin mRNA levels declined extensively (10- to 20-fold). Expression of mRNA from transfected hamster vimentin genes was reduced significantly in differentiating MEL cells. These results suggest that the divergence in vimentin expression in mammalian and avian erythropoiesis is due to a divergence of elements linked to vimentin sequences in cis. Our results further suggest the existence of general erythroid cellspecific trans-acting factors which have been functionally conserved from birds to mammals and interact with chicken vimentin regulatory sequences in murine erythroid cells in a manner appropriate for chicken vimentin sequences in a chicken erythroid cell environment.

\section{MATERIALS AND METHODS}

Construction of plasmid DNAs. Manipulations of DNA were carried out by standard protocols (54). For the transfection of adenine phosphoribosyltransferase (APRT)-deficient $\left(\right.$ aprt $\left.^{-}\right)$cells with chicken vimentin sequences, a plasmid containing the entire chicken vimentin gene, with 2.5-kilobase (kb) 5'- and 3'-flanking sequences, plus the hamster APRT gene was constructed in pUC18. A 3.7-kb HincII-BamHI fragment from a $\lambda$ genomic chicken vimentin recombinant, $\lambda V 8(10)$, containing the $5^{\prime}$ end of the gene plus 2.5-kb upstream sequences, was inserted into the polylinker region of pUC18 cleaved with HincII and BamHI. The resulting plasmid was then linearized with HincII, and this site was replaced by the ligation of $X h o I$ linkers, rendering plasmid $5^{\prime}$ VIMXB-1. The remainder of vimentin gene sequences, plus 3.8-kb 3'-flanking sequences contained in an 11.3-kb Bam HI fragment of $\lambda \mathrm{V8}$, were ligated to the BamHI site of p5'VIMXB-1, yielding plasmid pVIMXBB. A 1.3-kb fragment at the $3^{\prime}$ end of the chicken genomic insert was removed by digestion with Asp718 (an isoschizomer of $K p n I$ ), and hamster APRT gene sequences were inserted on a 4.0-kb BglII-Asp718 DNA fragment (53) by successive ligation of Asp718-generated cohesive ends, blunting of the remaining nonhomologous $A s p 718$ and $B g l I I$ ends with DNA polymerase I large fragment, and blunt-end ligation, yielding the final 20-kb plasmid, pAV21 (see Fig. 1a).

The hamster vimentin gene was isolated on a $14.5-\mathrm{kb}$ BamHI fragment (73) from a $\lambda$ EMBL3 genomic library prepared from size-fractionated, BamHI-digested BHK-21 DNA (data not shown). pAV21 was digested with HindIII and $B a m H I, B a m H I$ linkers were ligated to the polymeraseblunted ends (corresponding to the polylinker HindIII site and hamster APRT gene 5'-flanking BamHI site) of the 6.7-kb fragment containing the hamster APRT gene plus pUC18, and the DNA was circularized to yield pUC-APRT. The 14.5-kb BamHI fragment carrying hamster vimentin sequences was then ligated to the BamHI ends of pUCAPRT, yielding pAHV3 (see Fig. 1b).

Cell culture and transfections. An adherent aprt ${ }^{-}$MEL cell line, Faprt ${ }^{-} 585^{-} \mathrm{S}(14,20)$, was maintained at $37^{\circ} \mathrm{C}$ and $5 \%$ $\mathrm{CO}_{2}$ in Dulbecco modified eagle medium supplemented with $15 \%$ heat-inactivated fetal bovine serum and penicillinstreptomycin plus $50 \mu \mathrm{g}$ of 2,6-diaminopurine per ml (DAP medium) to continually select for the aprt ${ }^{-}$phenotype. Cells were cultured in the absence of DAP (neutral medium) for several days before DNA transfection. Two methods were used to introduce DNA into MEL cells. Poly-L-ornithinemediated transfections were carried out as described previously (6). At 16 to $20 \mathrm{~h}$ before DNA transfection, cells were plated at a density of $1 \times 10^{6}$ to $2.5 \times 10^{6}$ cells per $100-\mathrm{mm}$ (diameter) tissue culture dish. At the time of transfection, plates were washed once with Earle balanced salt solution and once with Tris-buffered saline $(25 \mathrm{~mm}$ Tris chloride, 137 $\mathrm{mM} \mathrm{NaCl}, 5 \mathrm{mM} \mathrm{KCl}, 1.4 \mathrm{mM} \mathrm{Na}_{2} \mathrm{HPO}_{4}, 10 \mathrm{mM} \mathrm{CaCl}, 5$ $\mathrm{mM} \mathrm{MgCl}_{2}, \mathrm{pH} 7.5$ ). One milliliter of Tris-buffered saline solution containing either $8 \mu \mathrm{g}$ of Asp718-cleaved pAV21 DNA plus $28 \mu \mathrm{g}$ of poly-L-ornithine or $4 \mu \mathrm{g}$ of DNA plus 10 $\mu g$ of poly-L-ornithine was added to each drained plate, and cells were incubated with the DNA-poly-L-ornithine solutions at $37^{\circ} \mathrm{C}$ for $3 \mathrm{~h}$ with occasional rocking of the plates. The DNA-poly-L-ornithine solutions were removed, and the plates were washed twice with Tris-buffered saline. Neutral medium was then added, and the cells were allowed to recover and express APRT activity for $18 \mathrm{~h}$. aprt ${ }^{+}$ transformants were then selected by incubation with medium containing $4 \mu \mathrm{g}$ of azaserine per ml and $15 \mu \mathrm{g}$ of adenine per ml (AZA-AD medium). Individual MEL cell colonies were isolated in cloning cylinders and expanded for further analysis. The efficiency of DNA transfer into Faprt $^{-} 585^{-} \mathrm{S}$ cells by this method was difficult to assess, since the concentrations of DNA and poly-L-ornithine used here were toxic to the cells and an undetermined number of cells was lost $(\geq 50 \%)$ when plates were washed after incubation with DNA-poly-L-ornithine. Nevertheless, we observed aprt ${ }^{+}$colonies in approximately one of every two to three plates, yielding a transfection efficiency of one aprt ${ }^{+}$ transformant per initial $\sim 4 \times 10^{6}$ to $1 \times 10^{7}$ cells. We also introduced DNA into Faprt ${ }^{-585^{-}} \mathrm{S}$ cells by calcium phosphate precipitation as previously described (91). Briefly, cells were plated in $10 \mathrm{ml}$ of neutral medium on $100-\mathrm{mm}$ tissue culture dishes at a density of $6 \times 10^{5}$ cells per plate at $18 \mathrm{~h}$ before addition of the calcium phosphate-DNA precipitate. One milliliter of precipitate containing $30 \mu \mathrm{g}$ of Asp 718cleaved pAV21 or pAHV3 DNA was added to each plate. Medium containing the calcium phosphate-DNA precipitate was removed after 20 to $22 \mathrm{~h}$ of incubation at $37^{\circ} \mathrm{C}$ and replaced with neutral medium for $24 \mathrm{~h}$. aprt $^{+}$transformants were then selected as described above. We observed aprt ${ }^{+}$ transformants at an approximate frequency of 1 per $2 \times 10^{6}$ to $5 \times 10^{6}$ cells. Cells transfected with pAV21 by the poly-L-ornithine protocol described above were designated $M E L C V O$ (chicken vimentin-ornithine), whereas calcium phosphate-generated transformants were designated $M E L C V$. The hamster vimentin construct was introduced into MEL cells only by calcium phosphate precipitation, and the resulting cells were designated $M E L A H V$.

Analysis of aprt ${ }^{+}$MEL transformants and isolation of RNA. aprt $^{+}$clones were grown and tested for the presence of exogenous vimentin sequences by genomic DNA blotting with appropriate vimentin-specific probes (data not shown). Cells containing either the entire chicken genomic portion of pAV21 or the entire $14.5-\mathrm{kb}$ BamHI hamster genomic fragment of pAHV3 were studied further. Cells were adapted to growth in bacterial dishes to facilitate differentiation (14) and cultured in AZA-AD medium (undifferentiated cells) or induced to differentiate in AZA-AD medium plus $1.8 \%$ DMSO for 4 to 5 days (30). Faprt ${ }^{-} 585^{-} \mathrm{S}$ cells were induced to differentiate for 4 days in DAP medium plus $1.8 \%$ DMSO. Cells were harvested, and total cellular RNA was prepared by the method of Chirgwin et al. (18) as modified (69). Spinal cord RNA from 1-week-old chickens was isolated as previously described (10), and cytoplasmic RNA was prepared from 15-day-old chicken embryo erythroid cells (63). Poly (A) ${ }^{+}$RNA was purified by oligo(dT)-cellulose chromatography (2). 
Determination of RNA levels by quantitative RNase protection mapping. Steady-state mRNA levels of chicken and murine vimentin, hamster APRT, mouse $\beta$-globin, and mouse $\gamma$-actin were assayed by protection of in vitrosynthesized complementary ${ }^{32} \mathrm{P}$-labeled RNAs from RNase digestion by cellular RNAs $(60,98)$. Several plasmids were constructed in pT7SP6 (3) for the synthesis of ${ }^{32} \mathrm{P}-\mathrm{RNA}$ probes (see below). For the detection of chicken vimentin $5^{\prime}$ sequences, the 3.7-kb HincII-BamHI fragment of $\lambda \mathrm{V8}$, containing exons 1 and 2 , was inserted into the respective polylinker sites in pT7SP6. For probe synthesis, the template was cleaved with HindIII, and a $1.9-\mathrm{kb}{ }^{32} \mathrm{P}$-labeled complementary RNA was generated with $\mathrm{T} 7$ phage polymerase (see Fig. 2b). A 1-kb chicken vimentin 3 '-specific probe was synthesized with $\mathrm{T} 7$ phage polymerase from a template consisting of $3^{\prime}$ untranslated sequences 143 nucleotides (nt) downstream of the translation termination codon (95a) through $0.6 \mathrm{~kb}$ of $3^{\prime}$-flanking sequences (see Fig. $4 \mathrm{~b}$ ). For $\beta$-globin RNA analysis, the 5' 1.9-kb EcoRI-BamHI fragment from the mouse $\beta$-major-globin genomic insert of pMB9- $\beta$ G2 (45) was subcloned (p $\beta 5^{\prime}$ ). A Bst NI-cleaved p $\beta 5^{\prime}$ template was transcribed with SP6 phage polymerase, yielding ${ }^{32} \mathrm{P}$-labeled RNA complementary to intervening sequence (IVS) 1 and exon 2 (see Fig. 3b). A hamster APRTspecific probe was synthesized with SP6 phage polymerase from a $B a m \mathrm{HI}$-cleaved template containing a 0.9-kb hamster APRT gene fragment (p5'APRT, see Fig. 3d). This probe is protected by exons 1 and 2 of APRT and also contains IVS 1 and a portion of IVS 2 sequences $(64,65)$. Mouse $\gamma$-actin RNA was detected with a probe synthesized from a human $\gamma$-actin template cloned in pSP64 (26).

${ }^{32} \mathrm{P}$-labeled complementary RNA probes were synthesized with SP6 or T7 phage polymerases, using the abovementioned templates, essentially under conditions described by Zinn et al. (98). [ $\left.\alpha{ }^{-32} \mathrm{P}\right] \mathrm{CTP}(3,000 \mathrm{Ci} / \mathrm{mmol})$ was diluted with unlabeled CTP and included in the transcription reactions at the following final concentrations and specific activities: $50 \mu \mathrm{M}$ at $200 \mathrm{Ci} / \mathrm{mmol}$ for $5^{\prime}$ vimentin, $50 \mu \mathrm{M}$ at 50 $\mathrm{Ci} / \mathrm{mmol}$ for $\beta$-globin, and $100 \mu \mathrm{M}$ at $100 \mathrm{Ci} / \mathrm{mmol}$ for APRT, $\gamma$-actin, and $3^{\prime}$ vimentin.

Typically, $1 \times 10^{5}$ to $2 \times 10^{5} \mathrm{cpm}$ of $\left[{ }^{32} \mathrm{P}\right] \mathrm{RNA}$ was hybridized to $10 \mu \mathrm{g}$ of MEL cell total RNA at $45^{\circ} \mathrm{C}$ for 14 to 17 $\mathrm{h}$ in $30 \mu \mathrm{l}$ of $80 \%$ formamide- $40 \mathrm{mM}$ PIPES (piperazine$N, N^{\prime}$-bis(2-ethanesulfonic acid) $-400 \mathrm{mM} \mathrm{NaCl}-1 \mathrm{mM}$ EDTA, pH 6.4. The hybridization reactions were then diluted with $300 \mu$ l of $20 \mathrm{mM}$ Tris chloride (pH 7.5)-300 mM NaCl-5 mM EDTA-50 $\mu \mathrm{g}$ of RNase A per ml-900 $U$ of RNase $\mathrm{T}_{1}$ per $\mathrm{ml}$ and incubated at $30^{\circ} \mathrm{C}$ for $1 \mathrm{~h}$. Ten microliters of $20 \%$ sodium dodecyl sulfate (SDS) and $100 \mu \mathrm{g}$ of proteinase $\mathrm{K}$ were added, and samples were digested at $37^{\circ} \mathrm{C}$ for 30 to $60 \mathrm{~min}$. Following phenol extraction, $10 \mu \mathrm{g}$ of carrier beef liver tRNA was added, and RNA was precipitated with ethanol. Protected [ $\left.{ }^{32} \mathrm{P}\right] \mathrm{RNA}$ fragments were resolved on 0.25 -mm-thick, $5 \%$ polyacrylamide- $8 \mathrm{M}$ urea denaturing gels (56) and exposed to Kodak XAR-5 film with intensifying screens.

For quantitation, ${ }^{32} \mathrm{P}$ radioactivity in gel slices was assayed by Cerenkov radiation, as detected in the ${ }^{3} \mathrm{H}$ channel of a Beckman model 1801 liquid scintillation counter; each sample was counted for $20 \mathrm{~min}$. Liquid scintillation counting of gel slices immersed in fluor gave similar results. The following gel slices were excised for quantitation: the 632-nt exon 1 fragment for chicken vimentin; the 209- and 81-nt fragments for $\beta$-major-globin and $\beta$-minor-globin, respectively; the 111-nt exon 2 fragment for hamster APRT; and the 80-nt fragment for mouse $\gamma$-actin. Radioactivity in gel slices was directly proportional to the amount of RNA hybridized, as determined by serial dilution of cellular RNAs (data not shown). In cases in which radioactivity was too low to be determined accurately (less than $2 \sigma$ above background $+2 \sigma$ ), autoradiograms using preflashed film were scanned with a densitometer, and peak areas were integrated. The data of Table 1 were derived from the gels shown in Fig. 2 and 3. Results qualitatively similar to the ones shown here were obtained in separate multiple determinations (data not shown).

Metabolic labeling with $\left[{ }^{35}\right.$ S]methionine and immunofluorescence microscopy. MEL cells cultured in the absence or presence of $1.8 \%$ DMSO for 4 days were labeled with $\left.{ }^{35} \mathrm{~S}\right]$ methionine for $1 \mathrm{~h}$ as described previously (69). Equivalent amounts of protein-incorporated $\left[{ }^{35} \mathrm{~S}\right]$ radioactivity in Triton X-100-insoluble residues $(5,62)$ from each sample were loaded on two-dimensional isoelectric focusing-SDSpolyacrylamide gels $(70)$; gels were stained with Coomassie blue to visualize total protein and then impregnated with 2,5-diphenyloxazole for fluorography (7). Immunofluorescence microscopy with an anti-chicken vimentin antiserum (33) was performed exactly as described previously (69).

Detection of hamster vimentin mRNA by quantitative primer extension analysis. An oligonucleotide with the sequence 5'-TGCGAACCGCGGGAGTGCTG-3' (synthesized at the Caltech Microchemical Facility) was labeled with T4 polynucleotide kinase in the presence of $\left[\gamma^{32} \mathrm{P}\right]$ ATP and used for primer extension analysis, essentially as described by Jones et al. (39). This oligonucleotide is complementary to hamster vimentin $\mathrm{mRNA}$ in the $5^{\prime}$ noncoding region, between positions 37 and 56 relative to the RNA initiation site (73). ${ }^{32} \mathrm{P}$-labeled oligonucleotide primer $(0.1 \mathrm{pmol})$ was hybridized to total cellular RNA for $2 \mathrm{~h}$ at $55^{\circ} \mathrm{C}$ in $10 \mu \mathrm{l}$ of 10 mM Tris chloride (pH 8)-250 mM NaCl-2 mM EDTA. Samples were diluted with $25 \mu$ l of $50 \mathrm{mM}$ Tris chloride $(\mathrm{pH}$ 8.7)-10 mM $\mathrm{MgCl}_{2}-5 \mathrm{mM}$ dithiothreitol-350 $\mu \mathrm{M}$ dATP, TTP, dCTP, and dGTP-10 $\mu \mathrm{g}$ of actinomycin D per ml-600 $\mathrm{U}$ of RNasin per ml-330 U of AMV reverse transcriptase (FPLC purified; Pharmacia) per $\mathrm{ml}$ and incubated for $1 \mathrm{~h}$ at $42^{\circ} \mathrm{C}$. Following phenol extraction and ethanol precipitation, extension products were separated on 0.25 -mm-thick $8 \%$ polyacrylamide $-8 \mathrm{M}$ urea gels and visualized by exposure to Kodak XAR-5 film in the presence of an intensifying screen. The 53- to 57-nt extension products, corresponding to correctly initiated hamster vimentin mRNA, were quantitated by Cerenkov radiation determination of excised gel slices. Serial dilution of BHK-21 RNA (a source of high levels of hamster vimentin RNA) over a 20 -fold range yielded a commensurate decrease in radioactive extension products (data not shown). Tripling the amount of ${ }^{32} \mathrm{P}$-labeled oligonucleotide primer in hybridizations had no effect on the amount of extension product synthesized (data not shown).

In vitro nuclear run-on transcriptions. Transcription in isolated nuclei was performed by an amalgam of several published procedures $(11,37,52,57)$. MEL cells were cultured for up to 4 days in the presence or absence of $1.8 \%$ DMSO. Cells were washed several times in phosphatebuffered saline and lysed in ice-cold reticulocyte standard buffer (10 mM Tris chloride, $10 \mathrm{mM} \mathrm{NaCl}, 5 \mathrm{mM} \mathrm{MgCl}$, pH 7.4) plus $0.5 \%$ Nonidet $\mathrm{P}-40,1 \mathrm{mM}$ dithiothreitol, and 50 to $100 \mathrm{U}$ of RNasin per ml. All subsequent steps were carried out at $0^{\circ} \mathrm{C}$, unless otherwise noted. Nuclei were pelleted by centrifugation at $1,000 \times g$ for $4 \mathrm{~min}$, and postnuclear supernatants were saved for preparation of cytoplasmic RNA by phenol-chloroform extraction. Nuclear pellets were rinsed gently in reticulocyte standard buffer alone, 
repelleted, and suspended in nuclear freezing buffer $(50 \mathrm{mM}$ Tris chloride [pH 8.0], $5 \mathrm{mM} \mathrm{MgCl}_{2}, 0.1 \mathrm{mM}$ EDTA, $40 \%$ [wt/vol] glycerol) at an approximate density of $10^{7}$ nuclei per $100 \mu \mathrm{l}$. Nuclei either were frozen and stored at $-70^{\circ} \mathrm{C}$ and thawed before use (experiment 1), or used immediately (experiment 2 and MEL-Fl transcriptions).

Each transcription reaction was carried out with $\sim 10^{7}$ nuclei. Nuclei were preincubated at $0^{\circ} \mathrm{C}$ for 5 to $10 \mathrm{~min}$ in nuclear freezing buffer, pelleted for 8 to $10 \mathrm{~s}$ in a variablespeed Eppendorf microcentrifuge (setting 5), and suspended in $50 \mu \mathrm{l}$ of nuclear freezing buffer. Fifty microliters of $2 \times$ run-on buffer (10 mM Tris chloride [pH 8], $300 \mathrm{mM} \mathrm{KCl,} 5$ $\mathrm{mM} \mathrm{MgCl} 2,1 \mathrm{mM}$ dithiothreitol, $10 \mathrm{mM}$ creatine phosphate, $0.1 \mathrm{mg}$ of creatine phosphokinase per $\mathrm{ml}, 1 \mathrm{mM}$ each ATP, CTP, and GTP) containing $320 \mu \mathrm{Ci}$ of $\left[\alpha-{ }^{32} \mathrm{P}\right] \mathrm{UTP}(\sim 3,000$ $\mathrm{Ci} / \mathrm{mmol}$ ) was added to each sample, and transcription was allowed to proceed for $15 \mathrm{~min}$ at $30^{\circ} \mathrm{C}$. We determined that incorporation of $\left[\alpha{ }^{32} \mathrm{P}\right] \mathrm{UTP}$ into RNA was linear for this duration at $30^{\circ} \mathrm{C}$ in both uninduced and induced nuclei (data not shown). Nuclei were iced, pelleted, suspended in $200 \mu \mathrm{l}$ of $20 \mathrm{mM}$ Tris chloride ( $\mathrm{pH} 7.5)-10 \mathrm{mM} \mathrm{MgCl}{ }_{2}-2 \mathrm{mM} \mathrm{CaCl}_{2}$ plus $40 \mu \mathrm{g}$ of carrier beef liver tRNA, and high-molecularweight DNA was digested with $75 \mathrm{U}$ of DNase I (FPLC purified; Pharmacia) at $30^{\circ} \mathrm{C}$ for $15 \mathrm{~min}$. Samples were digested by addition of $10 \mu \mathrm{l}$ of $20 \%$ SDS and $100 \mu \mathrm{g}$ of proteinase $\mathrm{K}$ and incubation at $42^{\circ} \mathrm{C}$ for 45 to $60 \mathrm{~min}$. RNA was isolated by phenol-chloroform extraction and ethanol precipitation and was separated from unincorporated [ $\alpha$ ${ }^{32}$ P]UTP by chromatography on 1-ml Sephadex G-50 (medium) spin columns. Within a given experiment, equivalent amounts of radioactivity $\left(3.5 \times 10^{6} \mathrm{cpm}\right.$ in experiment $1,7.0$ $\times 10^{6} \mathrm{cpm}$ in experiment 2 , and $1 \times 10^{7} \mathrm{cpm}$ in MEL-Fl transcriptions) were hybridized to nitrocellulose filters in 1 ml of solution.

Plasmid DNAs were linearized and immobilized on nitrocellulose as described by Kafatos et al. (40), by using a Schleicher \& Schuell dot blot apparatus. Ten micrograms of each plasmid was applied to each dot. The plasmids used were pVIMXBB for detection of chicken vimentin gene transcription; pSThvim, a pT7SP6 recombinant containing the $14.5-\mathrm{kb}$ BamHI hamster vimentin genomic fragment, for mouse vimentin; $\mathrm{p} \beta 5^{\prime}$ for $\beta$-globin; $\mathrm{pSP} 64 \gamma$-actin for mouse $\gamma$-actin, pUC-APRT for hamster aprt; and pT7SP6 as a negative control. Filters were prehybridized at $65^{\circ} \mathrm{C}$ for $2 \mathrm{~h}$ in $20 \mathrm{mM}$ Tris chloride ( $\mathrm{pH} 7.5)-10 \mathrm{mM}$ EDTA-0.3 M $\mathrm{NaCl}-0.2 \%$ SDS ( $2 \times$ TESS), plus $0.25 \mathrm{mg}$ of beef liver tRNA per $\mathrm{ml}$ and $1 \times$ Denhardt solution. ${ }^{32} \mathrm{P}$-labeled RNA in TE was heated to $65^{\circ} \mathrm{C}$ for 2 to $3 \mathrm{~min}$, iced, and added to $1 \mathrm{ml}$ of $2 \times$ TESS $-0.1 \mathrm{mg}$ of beef liver tRNA per ml-1× Denhardt solution preheated to $65^{\circ} \mathrm{C}$ and hybridized in microcentrifuge tubes at $65^{\circ} \mathrm{C}$ for $45 \mathrm{~h}$ (experiment 1$), 61 \mathrm{~h}$ (experiment 2), or $66 \mathrm{~h}$ (MEL-Fl transcriptions). Filters were washed three times with $2 \times \mathrm{SSC}(1 \times \mathrm{SSC}$ is $0.15 \mathrm{M} \mathrm{NaCl}$ plus $0.015 \mathrm{M}$ sodium citrate, $\mathrm{pH} 7.0$ ) at $65^{\circ} \mathrm{C}$ for $30 \mathrm{~min}$ each and once with $2 \times \mathrm{SSC}$ at room temperature, digested with $5 \mu \mathrm{g}$ of RNase A per $\mathrm{ml}$ and $25 \mathrm{U}$ of RNase $\mathrm{T}_{1}$ per $\mathrm{ml}$ in $2 \times \mathrm{SSC}$ at $37^{\circ} \mathrm{C}$ for $30 \mathrm{~min}$, washed finally in three to four changes of $2 \times$ SSC $-0.2 \%$ SDS at $65^{\circ} \mathrm{C}$ for $30 \mathrm{~min}$ each, air dried, and exposed to preflashed Kodak XAR-5 film with intensifying screens. Radioactivity in each dot was quantitated by Cerenkov radiation as described above. For each individual filter, the radioactivity in the pT7SP6 dot (18 to $20 \mathrm{cpm}$, less than 1 or $2 \mathrm{cpm}$ over the machine background) was subtracted from the gross radioactivity of each of the other dots. Dilution of input radioactivity in the hybridization yielded comparable decreases in hybridized RNA. Inclusion of $2 \mu \mathrm{g}$ a

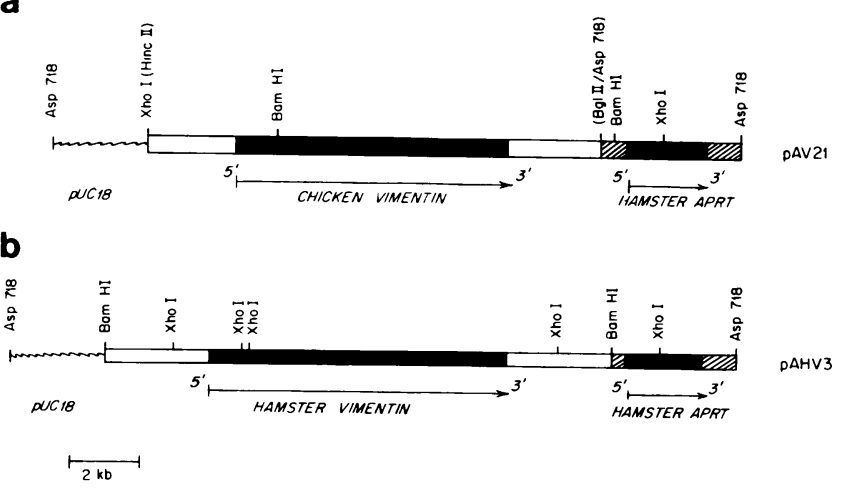

FIG. 1. Plasmid DNA constructs used for transfection of MEL cells. (a) Structure of pAV21, a chicken vimentin-hamster APRT plasmid. (b) Structure of pAHV3, a hamster vimentin-hamster APRT plasmid. Solid bars indicate gene coding regions. Open bars indicate vimentin flanking sequences, whereas hatched bars show APRT flanking sequences.

of $\alpha$-amanitin per $\mathrm{ml}$ in nuclear preincubations and transcriptions abolished all detectable radioactivity bound to the above-described plasmid dots, indicating that the transcription as assayed by our plasmids was due to RNA polymerase II activity $(41,51)$.

\section{RESULTS}

Transfection of MEL cells with the chicken vimentin gene. We constructed a plasmid, designated pAV21, specifically for the introduction of chicken vimentin gene sequences into APRT-deficient cells (Fig. 1a). pAV21 contains the entire 7.7-kb chicken vimentin gene coding sequence $(10,95 \mathrm{a})$, with 2.5-kb 5'- and 3'-flanking sequences, plus a 4.0-kb hamster genomic DNA fragment containing the hamster APRT gene (53). pAV21 was linearized with Asp718 and introduced into an aprt ${ }^{-}$MEL cell line, Faprt ${ }^{-} 585^{-} \mathrm{S}(14$, 20 ), by calcium phosphate precipitation (91) or poly-Lornithine-mediated transfection (6). Of 52 independent aprt ${ }^{+}$ MEL cell clones isolated and expanded for analysis, 28 possessed intact chicken vimentin gene sequences, as judged by genomic DNA blotting (data not shown). Using either method of transfection, the copy numbers of chicken vimentin genes ranged from 1 copy to $\sim 10$ to 20 copies per cell (data not shown; see Table 1).

Analysis of chicken vimentin mRNA expression in differentiating MEL cells. MEL cell lines harboring intact chicken vimentin sequences were either grown in the absence of chemical inducer (undifferentiated cells) or induced to differentiate by culturing in the presence of $1.8 \%$ DMSO for 4 to 5 days (30), and total cellular RNA was isolated. Chicken vimentin RNA was detected by quantitative RNase protection of a homogeneously labeled 1.9-kb $\left[{ }^{32} \mathrm{P}\right] \mathrm{RNA}$ probe specific for exons 1 and 2 (Fig. 2b). Figure 2a, lane 2, demonstrates protection of portions of the RNA probe corresponding to the 632-nt exon 1 and 61-nt exon 2 sequences of vimentin RNA from chicken embryo fibroblasts. This probe apparently also hybridizes to mouse vimentin RNA sequences, rendering a 70-nt protected fragment (Fig. 2a, lane 3; compare with tRNA control). This 70-nt fragment was not detected in RNAs from differentiated MEL cells (Fig. 2a, lane 4) and was absent from RNA preparations derived from other murine cell lines devoid of vimentin mRNA, such as the plasmacytomas MPC-11 and MOPC-31C 


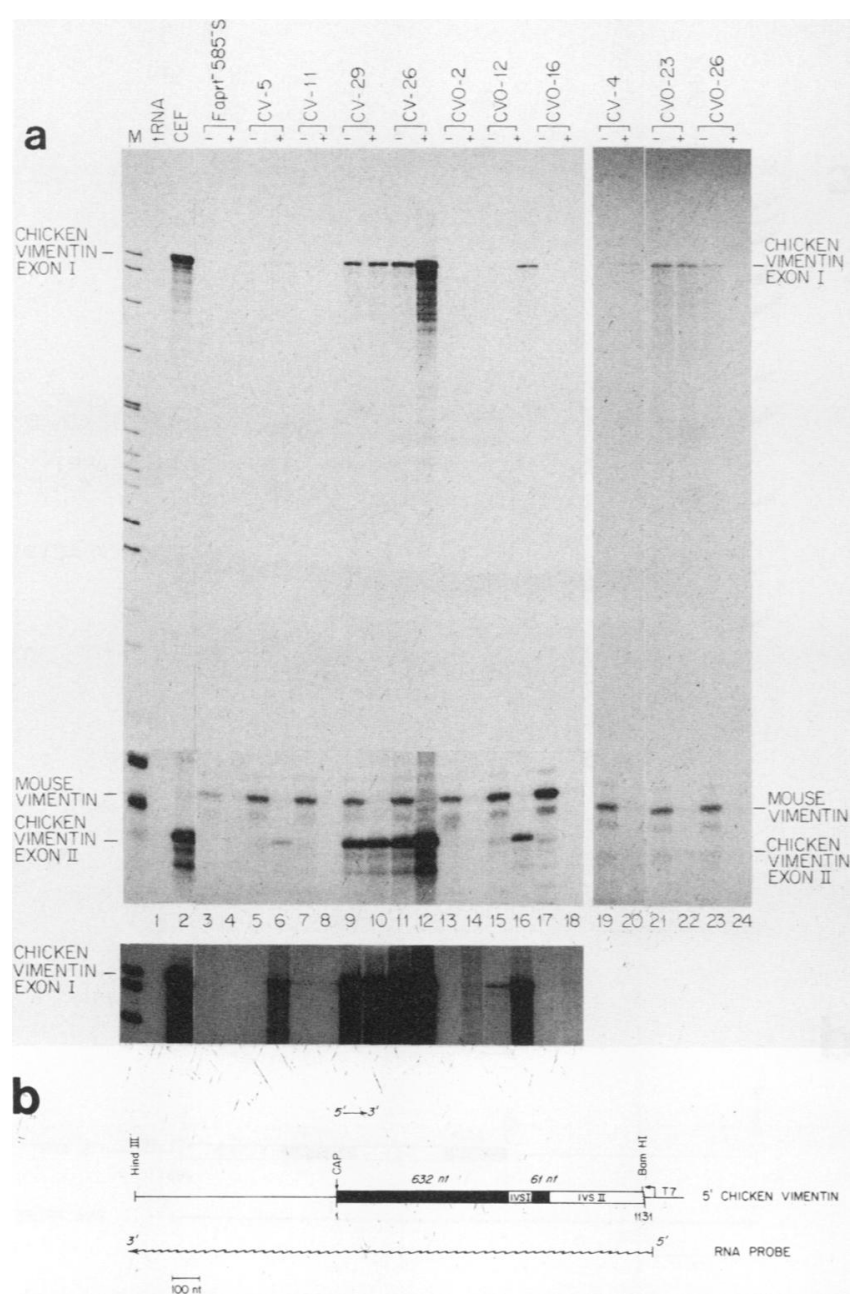

FIG. 2. Analysis of chicken vimentin RNA levels in undifferentiated and differentiated transfected MEL cells. (a) A ${ }^{32}$ P-labeled RNA probe complementary to exons 1 and 2 of chicken vimentin mRNA (panel b) was hybridized to cellular RNAs and subjected to RNase digestion as described in Materials and Methods. Protected fragments were resolved on denaturing polyacrylamide gels. Lanes: $\mathrm{M},{ }^{32} \mathrm{P}$-labeled pBR322-HpaII DNA markers; tRNA, protection of probe from RNase digestion after hybridization with $10 \mu \mathrm{g}$ of tRNA; CEF, protection with $2 \mu \mathrm{g}$ of chicken embryo fibroblast total RNA (fragments corresponding to the 632-nt exon 1 and 61-nt exon 2 were protected); 3 to 24, protection from $10 \mu \mathrm{g}$ of MEL cell RNAs from cells cultured in the absence $(-)$ or presence $(+)$ of $1.8 \%$ DMSO for 4 to 5 days. Note the protection of a 70-nt fragment by mouse vimentin RNA. The upper portion of lanes 1 to 18 was exposed for 1.5 days. To facilitate visualization of 60 - to 70 -nt fragments ( 10 -fold lower specific activity than the 632-nt exon 1 fragment), the lower portion of the same gel was exposed for 4.5 days. Lanes 19 to 24 were exposed for 4 days. For the lower panel, the upper region of lanes 1 to 18 was exposed for 4.5 days to show lowerintensity bands.

(58; data not shown). Ten MEL cell lines expressed correctly initiated chicken vimentin RNA at detectable levels (Fig. 2a, lanes 5 to 24). Seven cell lines, MELCV-4, $M E L C V-5, M E L C V-11, M E L C V-26, M E L C V O-2$, $M E L C V O-12$, and $M E L C V O-16$, induced the expression of chicken vimentin RNA 2- to 10-fold during differentiation (Fig. 2a; see Table 1). With the exception of MELCVO-26, the rest of the chicken vimentin-expressing cell lines maintained relatively constant levels of chicken vimentin RNA during DMSO-mediated differentiation. MELCVO-26 cells expressed chicken vimentin RNA only at very low levels, and upon differentiation, these levels decreased by approximately two- to fivefold. The variations in levels of expression and induction are typical for transfected genes in this and other systems (e.g., see reference 13). As an internal control, we observed that mouse vimentin RNA levels decreased by $>10$-fold during differentiation of all MEL cell lines, as judged by the 70 -nt fragment protected by mouse vimentin RNA sequences (Fig. 2a).

Among the cell lines which induced chicken vimentin RNA during DMSO-mediated differentiation, MELCV-5, $M E L C V-26$, and $M E L C V O-12$ expressed the chicken RNA after differentiation at levels comparable to or greater than the levels of endogenous mouse vimentin RNA found in undifferentiated cells (compare the 70-nt protected fragment of mouse vimentin with the 61-nt protected fragment of chicken vimentin in lanes 5 and 6, 11 and 12, and 15 and 16). Experiments similar to the one shown in Fig. 2a were performed several times, with results qualitatively similar to those shown here (data not shown).

Analysis of $\beta$-globin RNA levels in transfected MEL cells. To assess the extent of differentiation of each of the cell lines expressing chicken vimentin RNA, we analyzed the levels of $\beta$-globin RNA during differentiation of a selected subset of cell lines. A . 345-nt ${ }^{32}$ P-labeled RNA, complementary to mouse $\beta$-major-globin sequences from the $5^{\prime}$ end of the first intervening sequence (excluding the first $9 \mathrm{nt}$ ) to the $3^{\prime}$ end of exon 2 (excluding the last $13 \mathrm{nt}$ ) (45), was synthesized and used as a probe in RNase protection experiments (Fig. 3b). A 209-nt protected fragment corresponding to exon 2 of the $\beta$-major-globin mRNA was induced 50 -fold in the parent MEL' cell line (Fig. 3a, lanes 2 and 3; Table 1). Our $\beta$-major-globin probe also detected the presence of $\beta$-minorglobin transcripts, as evidenced by the protection of an 81-nt fragment, corresponding to homology with sequences between nucleotide positions 262 to 342 of $\beta$-major-globin (45). The pattern shown in lanes 2 and 3 indicates that the parent MEL cell line used in this study, Faprt ${ }^{-} 585^{-} \mathrm{S}$, exhibits a high ratio of $\beta$-minor-globin to $\beta$-major-globin RNA and expresses a significant amount of $\beta$-minor-globin RNA in the undifferentiated state; the induction of $\beta$-minor-globin RNA in these cells was three- to fourfold. As a comparison, the induction pattern of $\beta$-globin RNA from another MEL cell line, Mel-Fl, is shown in Fig. 3a, lanes 18 and 19. This MEL cell line produces mainly $\beta$-major-globin RNA upon differentiation and comparatively little $\beta$-minor-globin RNA in either the undifferentiated or differentiated state. Variations in $\beta$-major-globin and $\beta$-minor-globin ratios in different MEL cell lines have been described previously (1). Figure $3 a$, lanes 4 to 17, and Table 1 show that MELCV-5, MELCV-11, $M E L C V-26, M E L C V-29, M E L C V O-2, M E L C V O-12$, and $M E L C V O-16$ all induced $\beta$-major-globin RNA by $10-$ to 120 -fold (mean, 43-fold) and $\beta$-minor-globin RNA by 2.5 - to 7-fold (mean, 4-fold). Hence, the increases in chicken vimentin RNA in differentiating MEL cells occurred in cells undergoing extensive differentiation, as judged by $\beta$-globin RNA induction.

Analysis of hamster APRT and mouse $\boldsymbol{\gamma}$-actin RNA levels in transfected MEL cells. The specificity of induction of chicken vimentin RNA levels in differentiating MEL cells was established by assaying levels of hamster APRT RNA. If the transfected vimentin and APRT genes are independently expressed in our cell lines, then we expect to find little or no correlation in the respective steady-state mRNA levels during differentiation. We also measured endogenous $\gamma$-actin 

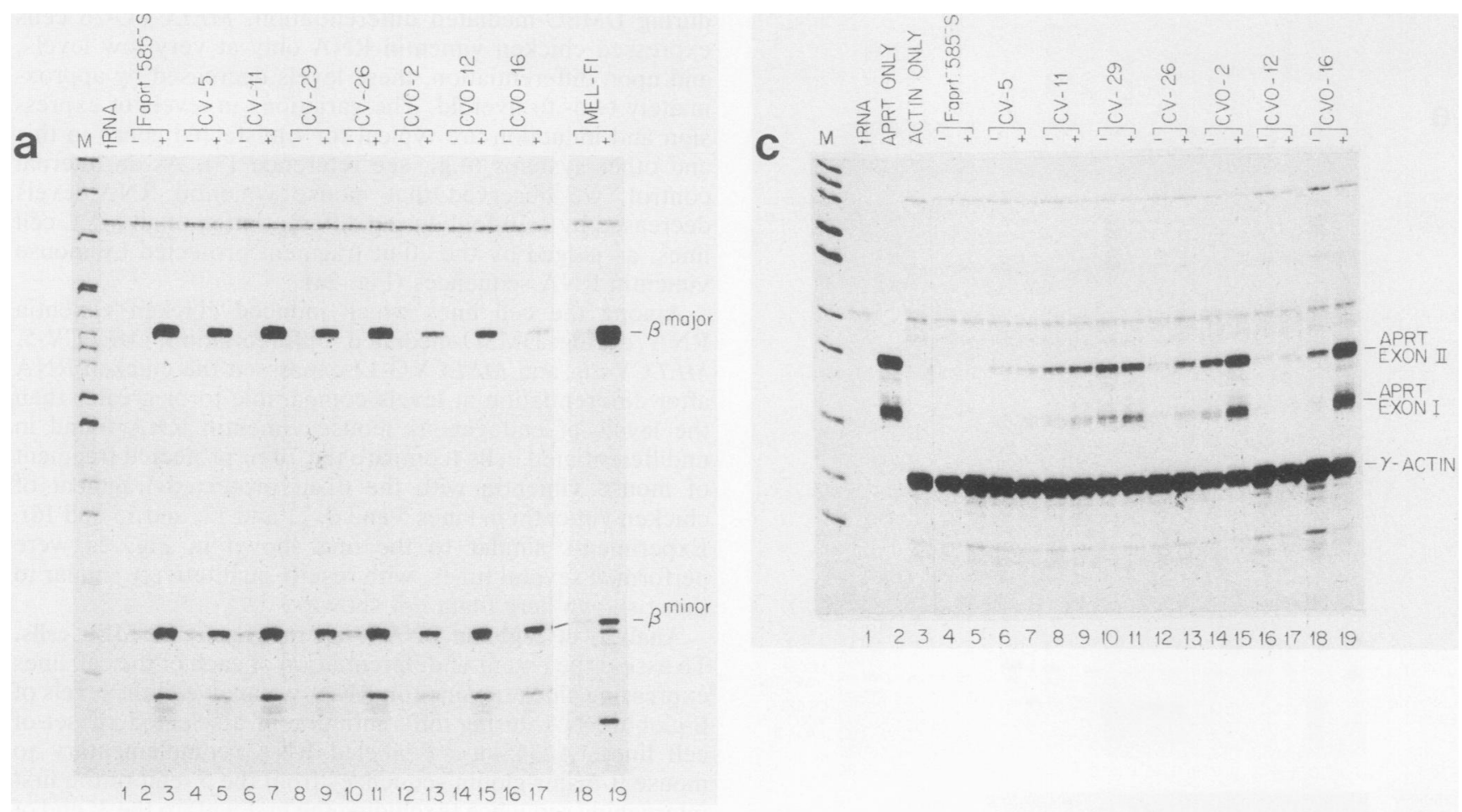

b
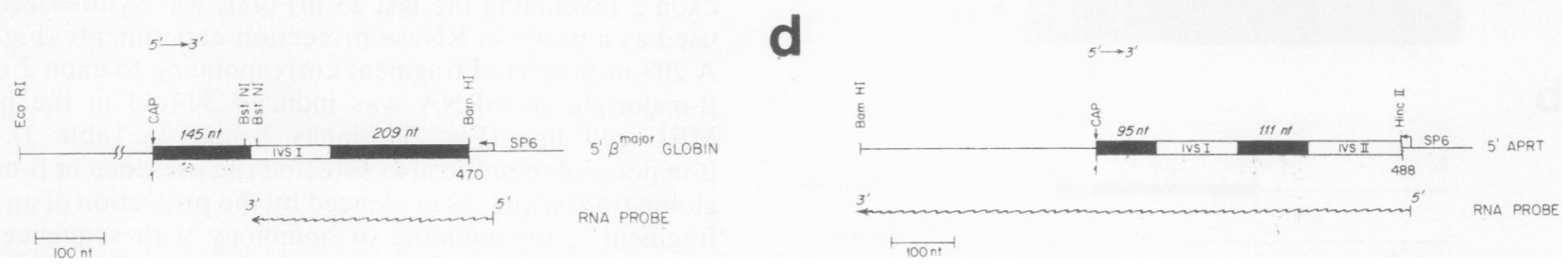

FIG. 3. Analysis of $\beta$-globin, hamster APRT, and mouse $\gamma$-actin RNA levels in MEL cells. (a) $\beta$-Globin RNA analysis. A ${ }^{32}$ P-labeled RNA probe for mouse $\beta$-major-globin (panel b) was used for RNase protection and electrophoretic analysis as described in Materials and Methods and the legend of Fig. 2. The $\beta$-major-globin probe was protected by both $\beta$-major-globin mRNA (209-nt fragment) and $\beta$-minor-globin mRNA (81-nt fragment). Lanes: M, ${ }^{32}$ P-labeled pBR322-HpaII markers; tRNA, tRNA (10 $\left.\mu \mathrm{g}\right)$ control; 2 to 19 , protection from $10 \mu \mathrm{g}$ of RNA isolated from uninduced (-) and induced (+) MEL cells. The RNAs used in this assay, as well as in the assay in panel c, were from the same preparations used for the experiments shown in Fig. 2. (c) Hamster APRT and mouse $\gamma$-actin RNA analysis. A mixed ${ }^{32}$ P-labeled RNA probe consisting of a complementary $\gamma$-actin RNA (26) and a complementary hamster APRT RNA (panel d) was used as described above. Protection of the APRT probe generated fragments of $111 \mathrm{nt}$ (exon 2) and $95 \mathrm{nt}$ (exon 1); protection of the $\gamma$-actin probe yielded an 80-nt fragment. Lanes: M, pBR322-Hpall markers; tRNA, protection of mixed probe after hybridization with $10 \mu \mathrm{g}$ of tRNA; 2 and 3, protection of $10 \mu \mathrm{g}$ of $M E L C V O-16$ (induced) RNA with the APRT probe only or actin probe only, respectively; 4 to 19 , protection of the mixed probe with $10 \mu \mathrm{g}$ of MEL cell RNA from DMSO-induced $(+)$ or uninduced $(-)$ cells.

RNA levels, since actin RNA levels are expected to exhibit little, if any, change during MEL cell differentiation (69). MEL cell RNAs were hybridized to a mixture of two ${ }^{32} \mathrm{P}$-labeled RNA probes. The hamster APRT-specific probe is a 0.9-kb RNA complementary to the 95-nt exon 1 and the 111-nt exon 2 of the APRT gene transcript (Fig. 3d). The $\gamma$-actin-specific probe is a complementary RNA derived from human $\gamma$-actin $3^{\prime}$ sequences and protects an 80-nt fragment from mouse $\gamma$-actin RNA (26). Figure 3c shows RNase protection experiments that measured simultaneously the steady-state levels of APRT and mouse $\gamma$-actin RNAs. Quantitation of this gel is tabulated in Table 1. A comparison of hamster APRT RNA levels with chicken vimentin RNA levels reveals no direct correlation in either the amounts of RNA accumulated (compare Fig. 2a and 3c) or the ratios of RNAs in induced versus uninduced cells (Table 1). Mouse $\gamma$-actin RNA levels varied less than twofold during MEL cell differentiation (Table 1), and the differences observed most likely reflect clonal variations of MEL cell isolates or variable levels of expression during particular DMSO inductions.

Utilization of chicken vimentin gene polyadenylation signals. An interesting feature of the chicken vimentin gene is the occurrence and utilization of multiple polyadenylation sites $(95 \mathrm{a}, 96,97)$. Four consensus polyadenylation signals (5'-AATAAA-3' [4]) reside $250,298,533$, and 554 nt downstream from the translation termination codon $(95 \mathrm{a}, 96)$; however, only polyadenylation signals the second through fourth are utilized in the chicken tissues examined (97), producing $\sim 2.0$ - and $\sim 2.3-\mathrm{kb}$ mRNAs $(10,96)$. The utilization of chicken vimentin polyadenylation sites is tissue specific; definitive erythroid cells accumulate predominantly the 2.0-kb mRNA, whereas other tissues and cell types accumulate more equivalent amounts of the 2.0- and 2.3-kb mRNAs (10). A comparison of hamster and chicken vimentin gene sequences at their $3^{\prime}$ ends reveals that the 
TABLE 1. Quantitation of steady-state RNA levels in undifferentiated and differentiated MELCV and MELCVO cells

\begin{tabular}{|c|c|c|c|c|c|c|}
\hline \multirow[b]{2}{*}{ Cell line } & \multirow{2}{*}{$\begin{array}{l}\text { Approximate no. of } \\
\text { transfected genes/cell }{ }^{a}\end{array}$} & \multicolumn{5}{|c|}{ Steady-state RNA ratio (differentiated level/undifferentiated level) of: } \\
\hline & & $\begin{array}{l}\text { Chicken } \\
\text { vimentin }\end{array}$ & $\begin{array}{l}\text { Hamster } \\
\text { APRT }^{b}\end{array}$ & $\begin{array}{c}\text { Mouse } \\
\beta \text {-major-globin }\end{array}$ & $\begin{array}{c}\text { Mouse } \\
\beta \text {-minor-globin }\end{array}$ & Mouse $\gamma$-actin ${ }^{b}$ \\
\hline$M E L$ Faprt $^{-} 585^{-} \mathrm{S}$ & 0 & $-^{c}$ & - & 50 & 3.7 & 1.7 \\
\hline$M E L C V-5$ & $10-20$ & $4^{b}$ & 1.0 & 9.1 & 2.5 & 0.7 \\
\hline$M E L C V-11$ & $10-20$ & $2^{d}$ & 1.2 & 39 & 3.7 & 1.0 \\
\hline$M E L C V-26$ & 1 & $2.9^{b}$ & 1.9 & 35 & 2.9 & 0.9 \\
\hline$M E L C V-29$ & $10-20$ & $1.2^{b}$ & 1.2 & 35 & 3.8 & 1.2 \\
\hline$M E L C V O-2$ & $2-4$ & $\geq 10^{d}$ & 1.6 & 42 & 3.4 & 1.0 \\
\hline MELCVO-12 & 1 & $9^{b}$ & 1.3 & 120 & 7.2 & 0.7 \\
\hline$M E L C V O-16$ & $2-4$ & $\geq 5-10^{d}$ & 3.2 & 40 & 3.8 & 0.5 \\
\hline$M E L C V-4$ & 1 & $3^{d}$ & $\mathrm{ND}^{e}$ & ND & ND & ND \\
\hline MELCVO-23 & 1 & $1^{d}$ & ND & ND & ND & ND \\
\hline$M E L C V O-26$ & 1 & $\leq 0.2-0.5^{d}$ & ND & ND & ND & ND \\
\hline
\end{tabular}

${ }^{a}$ Estimated from genomic DNA blots (data not shown).

${ }^{b}$ Determined by Cerenkov radiation in excised gel slices.

$c-$, No specific signals in these samples.

${ }^{d}$ Determined by densitometry of autoradiograms.

e ND, Not determined.

mammalian vimentin gene retains only one functional signal, corresponding to the second chicken polyadenylation site (73); both hamster and mouse cells produce $\sim 2.1-\mathrm{kb}$ vimentin mRNAs $(23,69)$. We therefore were interested in whether the mechanism by which polyadenylation signal 2 is preferentially utilized in definitive chicken erythoid cells has been conserved in mammals. To address this question, we analyzed chicken vimentin RNA from transfected MEL cells by performing RNase protection experiments with, as a probe, a 1-kb RNA complementary to chicken vimentin 3 -terminal sequences, from 143 nt downstream of the translation termination codon $(95 \mathrm{a})$ past the last polyadenylation signal (Fig. 4b). Chicken vimentin RNAs with 3' termini generated from polyadenylation signals 2,3 , and 4 protect 170-, 410-, and 430-nt fragments of the RNA probe (Fig. 4a, lanes 3,10 , and 11). Preferential utilization of polyadenylation signal 2 in 15-day-old chicken embryo erythroid cells (lanes 3 and 10) as compared with chicken spinal cord (lane 11) was demonstrated in this experiment, in agreement with previous findings (10). Total RNA from MEL cells expressing transfected chicken vimentin genes contains chicken vimentin RNAs with ratios of $3^{\prime}$ termini similar to those found in chicken nonerythroid cells. MELCV-26 and MELCV-29 cells accumulated similar ratios of chicken vimentin RNAs in both the undifferentiated and differentiatȩd states [lanes 4 to 7; compare with chicken definitive erythroid RNA (lanes 3 and 10) and chicken spinal cord poly $(A)^{+}$RNA (lane 11)]. All MEL cell lines that express detectable chickeń vimentin RNA displayed 3'-terminal patterns identical to those shown here for MELCV-26 and MELCV-29 (data not shown). Mouse fibroblastic $L$ cells transfected with pAV21 also accumulated ratios of chicken vimentin transcripts similar to those of transfected MEL cells (data not shown). The RNAs that exhibit these 3' termini in MEL cells are bona fide polyadenylated transcripts, as they are greatly enriched in the poly $(\mathrm{A})^{+}$RNA fraction [compare $10 \mu \mathrm{g}$ of total RNA from induced $M E L C V-26$ cells (lane 8) with $1 \mu \mathrm{g}$ of poly(A) ${ }^{+}$RNA derived from the same total RNA preparation (lane 9)]. From these experiments, we conclude that MEL cells do not discriminate among the multiple chicken vimentin polyadenylation sites in a manner specific to chicken definitive erythroid cells.

Transfected chicken vimentin genes produce functional mRNAs and vimentin filaments in differentiating MEL cells.
We examined one MEL cell line, $M E L C V-26$, for the synthesis and stabilization of vimentin protein. MELCV-26 cells contain high levels of chicken vimentin RNA, which increase approximately threefold after differentiation in the presence of DMSO (Fig. 2a, lanes 11 and 12, and 4a, lanes 4 and 5). Cells were maintained in control medium or induced to differentiate in medium containing $1.8 \%$ DMSO for 4 days, incubated with $\left[{ }^{35} \mathrm{~S}\right]$ methionine for $1 \mathrm{~h}$, and fractionated with Triton X-100. Equivalent amounts of Triton X-100insoluble protein-incorporated radioactivity were analyzed by two-dimensional gel electrophoresis; this material represents newly synthesized, newly assembled cytoskeletal protein $(5,62)$. Even though newly synthesized and assembled mouse vimentin was greatly reduced after differentiation in both the parent cell line (Fig. 5a and b) and MELCV-26 cells (panels $c$ and $d$ ), newly synthesized and assembled chicken vimentin was not only present in undifferentiated cells (panel c) but increased in abundance upon differentiation (panel d). Liquid scintillation counting of excised gel spots revealed that chicken vimentin radioactivity increased 5- to 6-fold at 4 days of differentiation in $M E L C V-26$ cells, whereas mouse vimentin radioactivity decreased $\geq 4$ - to 5 -fold in these cells and 7- to 10-fold in the parent MEL cell line (data not shown). Cytoskeletal chicken vimentin accumulated to high steady-state levels after DMSO induction of MELCV-26 cells, as judged by Coomassie blue staining of the gels (panels e and f), whose autoradiograms are shown in panels c and d.

To ascertain whether cytoskeletal chicken vimentin was present in a filamentous configuration, we performed indirect immunofluorescence microscopy on undifferentiated and differentiated MEL cells, using a vimentin-specific antiserum (33). Figure $6 \mathrm{~b}$ and $d$, show that vimentin filaments were lost during differentiation of the parent MEL cell line, in accordance with our previous observations using another MEL cell line, MEL-Fl (69). When we examined MELCV-26 cells, however, we observed a striking array of intensely fluorescent vimentin filaments in both undifferentiated and differentiated cells (Fig. 6f and h). In several experiments, we found that all of the MELCV-26 cells were vimentinpositive, both before and after DMSO induction, indicating that the transfected vimentin gene was expressed in all cells in the population. Since the composition of cytoskeletal vimentin in differentiated $M E L C V-26$ cells is predominantly, if not exclusively, chicken vimentin, the array shown in Fig. 

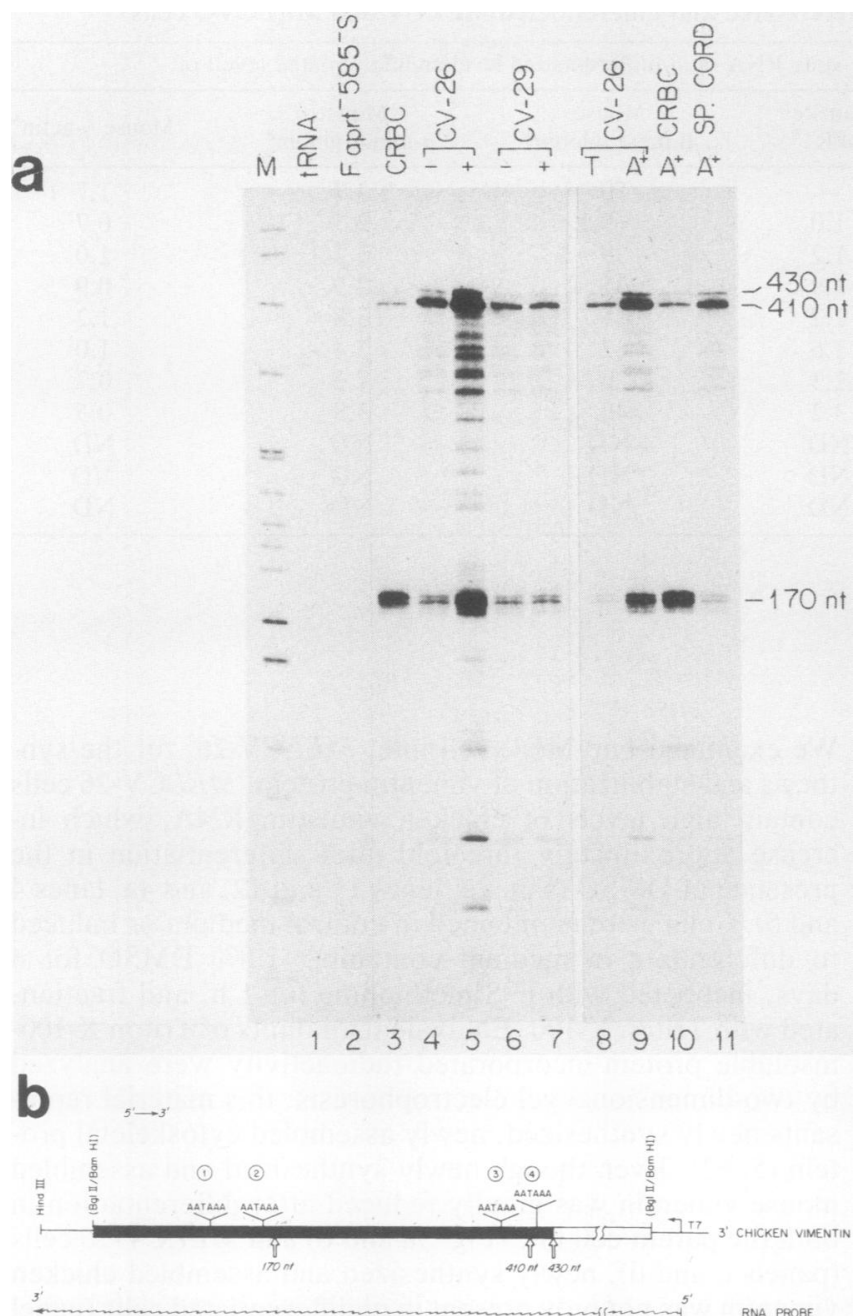

FIG. 4. Analysis of chicken vimentin RNA 3' termini. Utilization of chicken vimentin RNA 3' termini was determined by protection of the ${ }^{32} \mathrm{P}$-labeled RNA probe shown in panel $\mathrm{b}$. The positions of the consensus polyadenylation signals $\left(5^{\prime}\right.$-AATAAA- $\left.3^{\prime}\right)$ are indicated (95a). The sites are numbered 1 through 4 , in a $5^{\prime}$-to-3' direction. The expected sites of $3^{\prime}$ termini, together with the predicted sizes of protected probe fragments $(170,410$, and $430 \mathrm{nt})$ are shown. (a) Protected probe fragments resolved on a denaturing polyacrylamide gel. Lanes: M, pBR322-HpaII markers; tRNA and Faprt ${ }^{-585^{-}}$S, negative controls showing probe protection after hybridization with $10 \mu \mathrm{g}$ of tRNA or Faprt ${ }^{-} 585^{-} \mathrm{S}$ (uninduced) RNA; 3, protection by $2 \mu \mathrm{g}$ of 15 -day-old chicken embryo erythroid cell total cytoplasmic RNA; 4 to 7, protection with $10 \mu \mathrm{g}$ of $M E L C V-26$ and MELCV-29 RNA from uninduced cells ( - ) or cells induced with 1.8\% DMSO for 4 days $(+) ; 8$ and 9 , protection by $10 \mu \mathrm{g}$ of total RNA and $1 \mu \mathrm{g}$ of poly(A) ${ }^{+}$RNA, respectively, from $M E L C V-26$ cells cultured in $1.8 \%$ DMSO for 3 days; 10 and 11 , protection patterns with $1 \mu \mathrm{g}$ of 15-day-old chicken embryo erythroid cell cytoplasmic poly(A) ${ }^{+}$ RNA and $1 \mu \mathrm{g}$ of 1 -week-old chick spinal (sp.) cord poly(A) ${ }^{+}$RNA, respectively. Lanes 1 to 7 were exposed for $48 \mathrm{~h}$, and lanes 8 to 11 were exposed for $7 \mathrm{~h}$. CRBC, Chicken erythrocytes.

$6 \mathrm{~h}$ is due to the presence of chicken vimentin filaments. Hence, differentiating $M E L C V-26$ cells accumulate filamentous chicken vimentin during differentiation while simultaneously losing mouse vimentin. The results of Fig. 5 and 6 were also confirmed in another cell line, $M E L C V-5$; by both immunoblot and immunofluorescence analysis, we found that chicken vimentin accumulated and formed filaments during differentiation of MELCV-5 cells, whereas endogenous mouse vimentin was lost (data not shown).

Expression of hamster vimentin genes in differentiating MEL cells. The data presented thus far indicate that MEL cell lines transfected with chicken vimentin genes accumulate either increasing or constant amounts of both the chicken mRNA and protein during DMSO-mediated differentiation. However, we could not rule out the possibility that the induction (or lack of repression) of chicken vimentin mRNA was due to aberrations of DNA transfection. We therefore transfected MEL cells with a cloned hamster vimentin gene. The plasmid construct used for this purpose, pAHV3, is analogous to pAV21, the chicken vimentin plasmid. In pAHV3 we substituted the chicken genomic sequences and $\sim 400$ base pairs of hamster APRT gene 5'flanking sequences with a 14.5-kb genomic DNA fragment containing the entire hamster vimentin gene (73) (Fig. 1). The hamster vimentin gene lies in the same orientation relative to vector and APRT gene sequences as the chicken gene does in pAV21 and is surrounded by $\sim 3-\mathrm{kb} 5^{\prime}-$ and 3'-flanking sequences. pAHV3 DNA was linearized with Asp 718 and introduced into Faprt $^{-} 585^{-} \mathrm{S}$ cells by calcium phosphate transfection. Seven independent cell lines containing intact hamster vimentin gene sequences were obtained and used for subsequent analysis. To assay hamster vimentin RNA levels, we performed quantitative primer
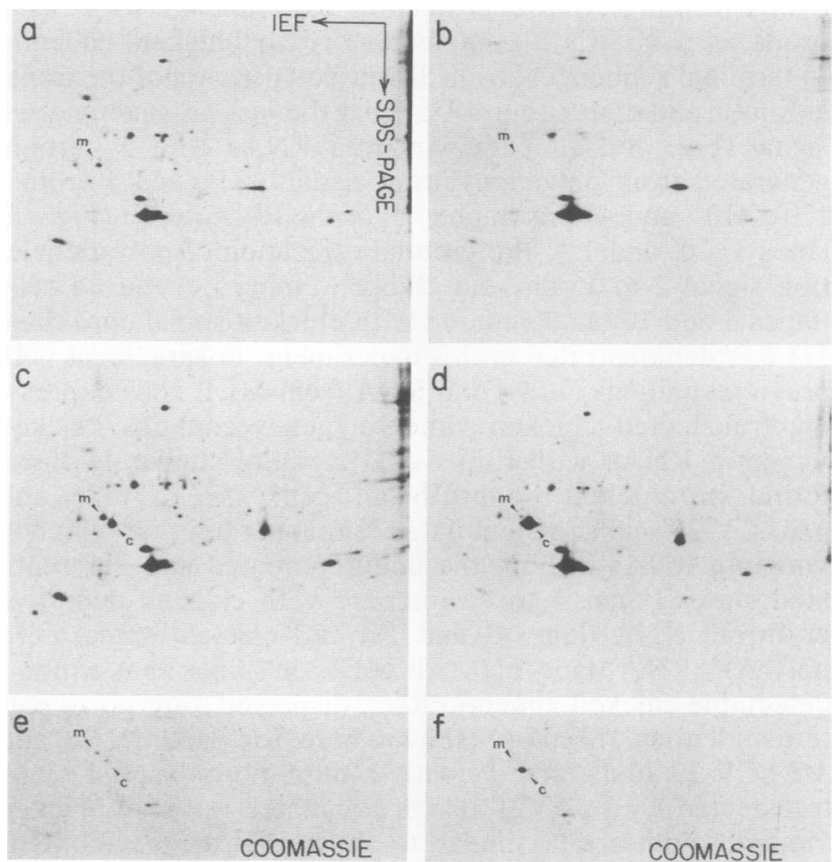

d
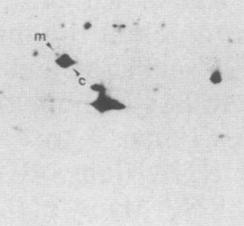

FIG. 5. Analysis of newly assembled vimentin by twodimensional gel electrophoresis. MEL cells were grown in the absence or presence of $1.8 \%$ DMSO for 4 days, labeled for $1 \mathrm{~h}$ with $\left.{ }^{35} S\right]$ methionine, and fractionated with Triton X-100. Equivalent amounts of protein-incorporated radioactivity from insoluble residues were electrophoresed and fluorographed (panels a to d). Panels: a, Uninduced parental Faprt ${ }^{-585}$-S MEL cells; b, induced Faprt ${ }^{-585^{-}} \mathrm{S}$ cells; c, uninduced $M E L C V-26$ cells; d, induced MELCV-26 cells (migrations of mouse [m] and chicken [c] vimentin are indicated); e and $\mathrm{f}$, portions of Coomassie blue-stained gels whose fluorographs are shown in panels $c$ and d, respectively. IEF, Isoelectric focusing; SDS-PAGE, SDS-polyacrylamide gel electrophoresis. 

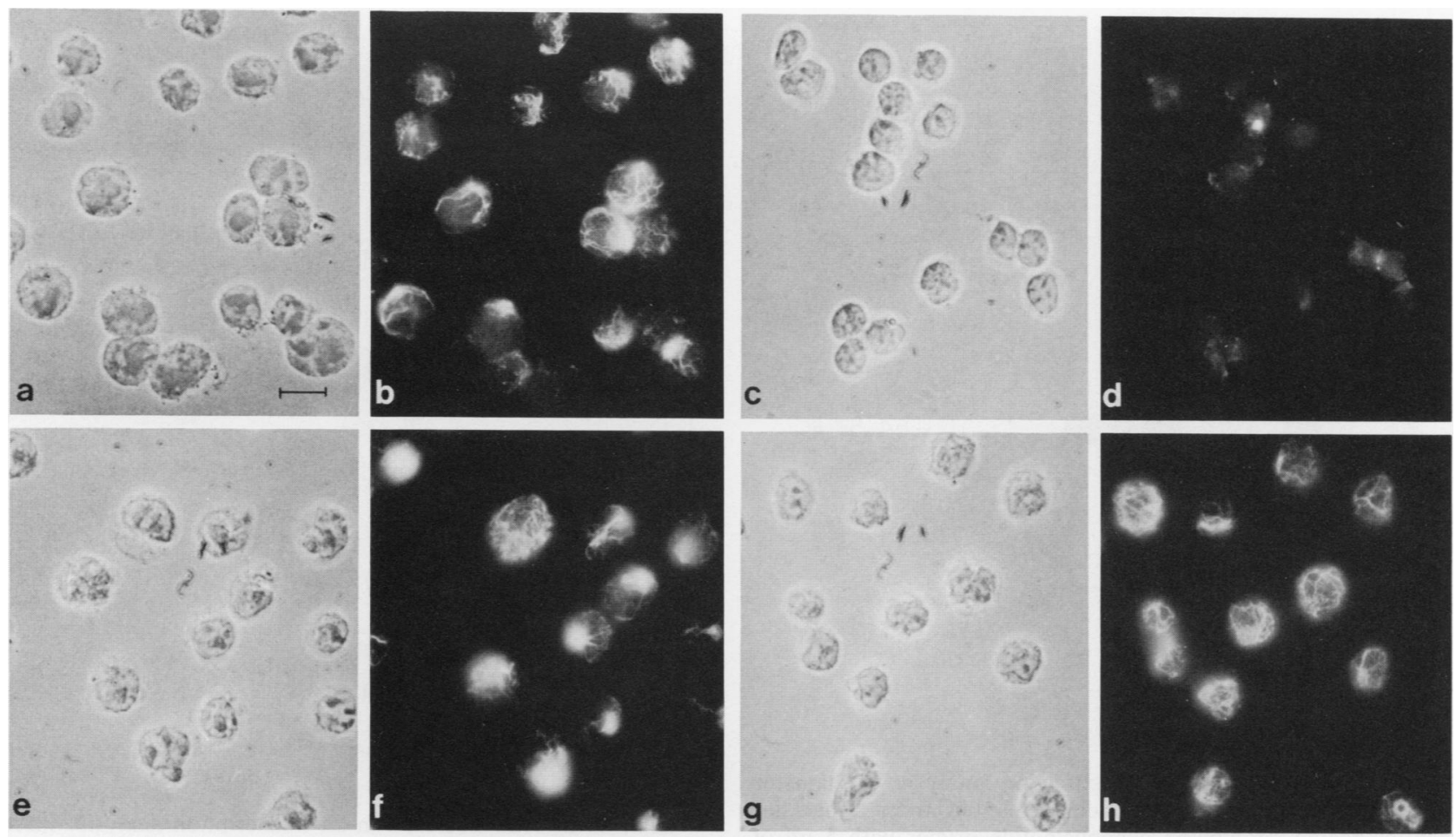

FIG. 6. Vimentin-specific immunofluorescence microscopy. MEL cells were cultured in the absence (panels a, b, e, and f) or presence (panels c, $\mathrm{d}, \mathrm{g}$, and $\mathrm{h}$ ) of $1.8 \%$ DMSO for 4 days and prepared for immunofluorescence microscopy with a vimentin-specific antibody. Cells were visualized with phase-contrast (panels a, c, e, g) and epifluorescence (panels b, d, f, h) optics. Bar, $10 \mu \mathrm{m}$.

extension analysis, using a ${ }^{32} \mathrm{P}$-labeled oligonucleotide complementary to hamster vimentin mRNA 37 to 56 nt downstream from the predicted cap site (73). Figure 7, lane 1, shows the expected 53- to 57-nt primer extension product with BHK-21 RNA as a source of hamster vimentin transcript $(31,88)$. Primer extension with Faprt ${ }^{-} 585^{-} \mathrm{S}$ RNA as a template was negative (Fig. 7, lanes 2 and 3). Three cell lines, MELAHV-6, MELAHV-9, and MELAHV-12, expressed the hamster vimentin RNA at detectable levels, and all three showed significantly reduced levels of this RNA upon differentiation (lanes 4 to 9). Undifferentiated MELAHV-9 and MELAHV-12 cells accumulated hamster vimentin RNA at $\sim 5 \%$ of the levels found in BHK-21 cells. Upon differentiation, hamster vimentin RNA levels fell 2.5-fold in MELAHV-9 cells and 10-fold in MELAHV-12 cells (Table 2). The decrease in hamster vimentin RNA in MELAHV-6 cells was difficult to measure, as the levels in undifferentiated cells were low and declined below our limits of detection in differentiated cells; we estimate the decrease to be at least fivefold. Quantitation of APRT, $\gamma$-actin, and $\beta$-globin RNA levels confirmed that the decline in hamster vimentin RNA was specific and induction of $\beta$-globin RNA was extensive (Table 2).

Determination of vimentin gene transcription rates by in vitro nuclear run-on transcription analysis. Our observation that chicken vimentin RNA increased and murine or hamster vimentin RNA decreased during MEL cell differentiation suggests that the differences are due to cis-acting sequences. To establish the contribution of RNA transcription rates toward vimentin RNA accumulation levels, we performed in vitro nuclear run-on transcription analysis $(37,57)$. Nuclei were isolated from MEL cells cultured in the absence or presence of DMSO for 4 days and incubated with [ $\alpha$ ${ }^{32}$ P]UTP. ${ }^{32} \mathrm{P}$-labeled RNA was isolated, and transcription rates were determined by hybridization with excess filterbound DNAs. To determine the utility of this technique for our system, we performed run-on transcriptions using nuclei isolated from a MEL cell line (MEL-Fl) whose endogenous vimentin, $\beta$-globin, and actin RNA accumulation kinetics had been determined previously (69). In this cell line, steady-state vimentin RNA falls to $30 \%$ of control levels at $24 \mathrm{~h}, 10 \%$ at $48 \mathrm{~h}$, and $4 \%$ at $96 \mathrm{~h}$ of DMSO-induced differentiation; actin mRNA levels remain constant through $96 \mathrm{~h}$ of differentiation, whereas $\beta$-globin mRNA increases 3to 5-fold at $48 \mathrm{~h}$ and 10 - to 20 -fold at $96 \mathrm{~h}$ (69). Figure 8a and Table 3 show the results of nuclear run-on transcriptions in nuclei obtained from MEL-Fl cells grown in control medium or in the presence of DMSO for 24,48 , and $96 \mathrm{~h}$. $\beta$-Globin transcription increased to a maximum of 12 -fold over control levels at $96 \mathrm{~h}$, and actin transcription remained fairly constant, falling to only $74 \%$ after $96 \mathrm{~h}$ of differentiation. Surprisingly, murine vimentin gene transcription at $24 \mathrm{~h}$ of differentiation decreased only slightly, to $56 \%$ of control levels, and transcription of this gene was maintained at $\sim 40 \%$ through $96 \mathrm{~h}$ of differentiation. Similar results were obtained with Faprt ${ }^{-} 585^{-} \mathrm{S}$ cells; in two independent experiments, murine vimentin transcription decreased to only $40 \%$ of control levels at $96 \mathrm{~h}$ of DMSO-induced differentiation (Fig. 8b; Table 4). Blot analysis of cytoplasmic RNAs from the same cell preparations used in these experiments confirmed the extensive decline (10- to 20-fold) in vimentin mRNA steady-state levels in both MEL-Fl and Faprt ${ }^{-585^{-} \mathrm{S}}$ cells at $96 \mathrm{~h}$ of differentiation (data not shown). Induction of $\beta$-globin gene transcription was only 3.5- to 5-fold in $\mathrm{Faprt}^{-}$ $585^{-} \mathrm{S}$ cells; this was due to the high level of $\beta$-minor-globin expression in the undifferentiated state (Fig. 3a, lanes 3 and 4).

In two independent experiments with $M E L C V-26$ nuclei, 


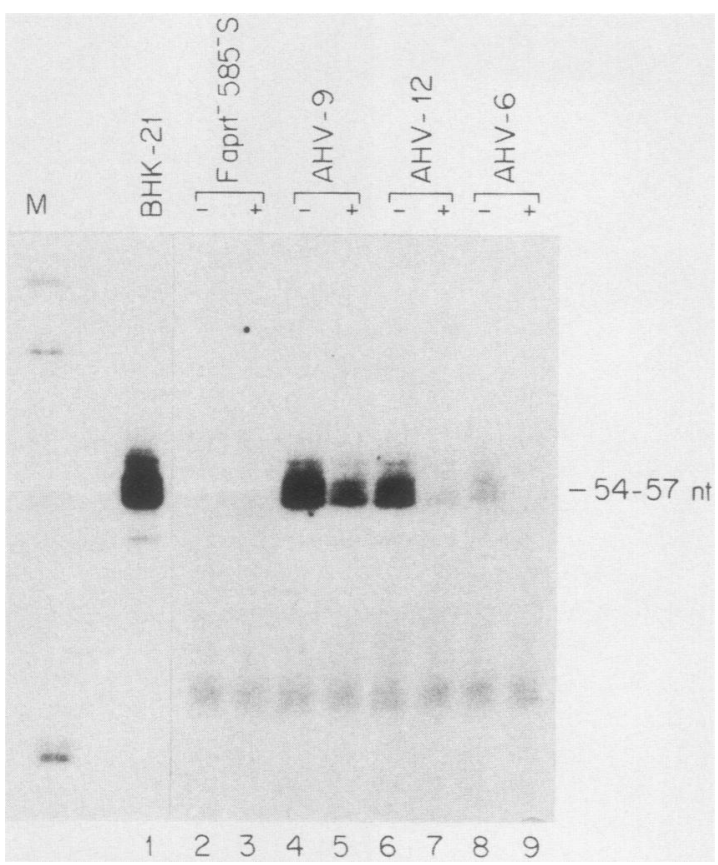

FIG. 7. Quantitative primer extension analysis of hamster vimentin RNA. Extension products generated from a hamster vimentin-specific ${ }^{32} \mathrm{P}$-labeled oligonucleotide primer with $5 \mu \mathrm{g}$ of total cellular RNA templates were resolved on an $8 \%$ polyacrylamide-8 $\mathrm{M}$ urea gel. One-half of each sample was loaded on the gel. The positions of 54- to 57-nt products, corresponding to correctly initiated hamster vimentin mRNA, are indicated. Lanes: $M$, pBR322-HpaII markers; 1, BHK-21 RNA; 2 to 9, MEL cell line RNAs from cells grown in the absence $(-)$ or presence $(+)$ of DMSO for 4 days. Lane 1 was exposed for 1 day; lanes 2 to 9 were exposed for 7 days.

transcription of the introduced chicken vimentin gene increased 2.5- to 4-fold (Fig. 8c; Table 4), roughly paralleling the steady-state RNA levels (Table 1). APRT and $\beta$-globin gene transcription both increased about two- to threefold, approximating the increases in the respective steady-state amounts (Table 1). Transcription of the mouse vimentin gene in differentiated $M E L C V-26$ cells apparently decreased to only $\sim 70$ to $90 \%$ of control levels. This value is an overestimate, however, as the combination of high levels of chicken vimentin gene transcription and limited $(<10$ to $15 \%$ ) but variable cross-hybridization with the mammalian DNA sequences obscured the relatively lower mousespecific signal. On the basis of these in vitro transcription experiments, we conclude that the induction of chicken vimentin RNA in transfected MEL cells is due primarily to

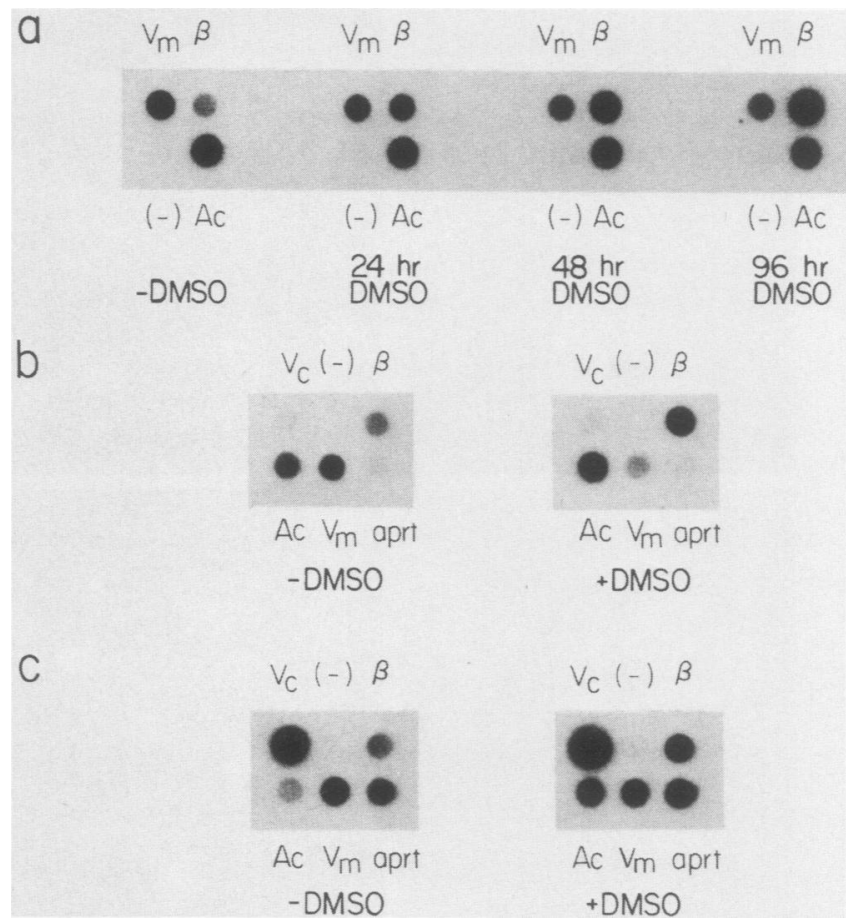

FIG. 8. In vitro nuclear run-on transcription analysis. Plasmid DNA dots immobilized to nitrocellulose were hybridized to ${ }^{32} \mathrm{P}$ labeled RNA synthesized in isolated MEL cell nuclei, washed, and exposed to X-ray film. Dots: $V_{m}$, detection of endogenous mouse vimentin gene transcription with pSThvim, a hamster vimentin DNA plasmid (a strong signal was readily obtained because of the high sequence homology among mammalian vimentin sequences [28]); $\beta, \beta$-globin; Ac, actin; $V_{c}$, chicken vimentin; aprt, hamster APRT; $(-)$, pT7SP6 vector DNA. Panels: a, transcription in isolated nuclei from MEL-Fl cells cultured in the absence or presence of $1.8 \%$ DMSO, as indicated; b and c, transcription in nuclei from parental Faprt ${ }^{-} 585^{-} \mathrm{S}$ cells or MELCV-26 cells (respectively) grown in the absence or presence of DMSO for 4 days. The data in panels $\mathrm{b}$ and $\mathrm{c}$ are from experiment 2 (see the text).

an increase in transcription, in contrast to a lesser change in the transcription of the endogenous vimentin gene relative to murine vimentin RNA levels. Actin transcription rates increased two- to threefold in Faprt ${ }^{-585^{-}} \mathrm{S}$ and MELCV-26 cells; in separate experiments, the former accumulated approximately twofold more actin RNA during differentiation, and the latter maintained actin RNA at constant levels (Table 1). Since the determinations of actin transcription were only performed once and steady-state actin mRNA was not measured within the same experiment, the observed disparity in $M E L C V-26$ actin gene transcription and RNA accumulation may not be significant.

TABLE 2. Quantitation of steady-state RNA levels in undifferentiated and differentiated MELAHV cells

\begin{tabular}{|c|c|c|c|c|c|c|}
\hline \multirow[b]{2}{*}{ Cell line } & \multirow{2}{*}{$\begin{array}{l}\text { Approximate no. of } \\
\text { transfected genes/cell }\end{array}$} & \multicolumn{5}{|c|}{ Steady-state RNA ratio (differentiated level/undifferentiated level) of: } \\
\hline & & $\begin{array}{l}\text { Hamster } \\
\text { vimentin }\end{array}$ & $\begin{array}{l}\text { Hamster } \\
\text { APRT }^{b}\end{array}$ & $\begin{array}{c}\text { Mouse } \\
\beta \text {-major-globin }\end{array}$ & $\begin{array}{c}\text { Mouse } \\
\beta \text {-minor globin }{ }^{b}\end{array}$ & Mouse $\gamma$-actin ${ }^{b}$ \\
\hline$M E L A H V-6$ & $2-4$ & $<0.2^{c}$ & 0.6 & 48 & 4.0 & 0.6 \\
\hline MELAHV-9 & $1-2$ & $0.4^{b}$ & 1.0 & 11 & 2.7 & 1.4 \\
\hline MELAHV-12 & $4-6$ & $0.1^{b}$ & 0.7 & 17 & 3.8 & 1.5 \\
\hline
\end{tabular}

${ }^{a}$ Estimated from genomic DNA blots (data not shown).

${ }^{b}$ Determined by Cerenkov radiation in excised gel slices (gels not shown for $\beta$-globin, APRT, and actin determinations).

$c$ See the text. 
TABLE 3. Transcription in nuclei isolated from MEL-Fl cells

\begin{tabular}{|c|c|c|c|c|c|c|}
\hline \multirow[b]{2}{*}{ Treatment } & \multicolumn{2}{|c|}{ Mouse vimentin } & \multicolumn{2}{|c|}{ B-Globin } & \multicolumn{2}{|c|}{ Actin } \\
\hline & $\mathrm{cpm}^{a}$ & $\begin{array}{l}\text { Fraction } \\
\text { of control }\end{array}$ & $\mathrm{cpm}^{a}$ & $\begin{array}{c}\text { Fraction } \\
\text { of control }\end{array}$ & $\mathrm{cpm}^{a}$ & $\begin{array}{c}\text { Fraction } \\
\text { of control }\end{array}$ \\
\hline No DMSO (control) & 83 & (1.0) & 20 & (1.0) & 142 & (1.0) \\
\hline DMSO (24 h) & 47 & 0.56 & 42 & 2.1 & 114 & 0.80 \\
\hline DMSO (48 h) & 32 & 0.39 & 116 & 5.8 & 110 & 0.78 \\
\hline DMSO (96 h) & 35 & 0.42 & 242 & 12 & 104 & 0.74 \\
\hline
\end{tabular}

${ }^{a}$ Net Cerenkov radiation, with background hybridization to pT7SP6 filter dots (18 to $20 \mathrm{cpm}$ ) subtracted.

\section{DISCUSSION}

Divergence of vimentin expression in avian and mammalian erythropoiesis is manifested in the expression of transfected vimentin genes in differentiating MEL cells. Differentiation of MEL cells in vitro has long served as a model system for mammalian erythropoiesis (30; reviewed in reference 55). Studies of exogenous globin genes introduced into MEL cells have delineated the cis-acting regulatory regions responsible for the induction of globin genes during erythropoiesis $(14,16,17,93,94)$. In the present study, we undertook MEL cell transfection experiments as an approach to understanding the molecular basis for divergent vimentin gene regulation in avian and mammalian erythropoiesis.

Two simple alternative mechanisms can explain the observed differences in vimentin regulation in avian and mammalian erythropoiesis. For both mechanisms, we presume that expression of vimentin genes is regulated by interactions of trans-acting regulatory factors with cis-linked sequences. In the first mechanism, a divergence in trans-acting regulatory factors is responsible for the differences in expression. In avian erythroid cells, the vimentin gene is either activated or derepressed by a trans-acting factor during terminal differentiation. In mammals, however, this activating factor either is absent or has been replaced or overridden by the activity of another factor, resulting in the repression of vimentin RNA levels during erythropoiesis. If vimentin cis-acting regulatory sequences have been conserved, we predict that transfected chicken vimentin genes would be negatively regulated in differentiating MEL cells.
In the second mechanism, divergent cis-acting vimentin regulatory elements are responsible for activation (or derepression) in avian erythropoiesis and repression (or deactivation) in mammalian erythropoiesis. The observed differences in gene expression therefore would be attributable to changes in the target vimentin sequence itself. This mechanism predicts that a transfected chicken vimentin gene would not be regulated in a manner appropriate for the differentiating host murine erythropoietic cell. Furthermore, if positively acting factors that activate the vimentin gene in chicken erythroid cells have been conserved in mammals as part of the general erythropoietic program (as we would expect them to be if they regulate the expression of a number of genes), then we would predict transfected chicken vimentin genes to be activated or derepressed in differentiating MEL cells.

Our results are consistent with the second mechanism described above. Chicken vimentin RNA levels either increased significantly (2- to 10 -fold) or remained constant in the majority of the chicken vimentin-expressing MEL cell lines undergoing DMSO-mediated differentiation. The increase in chicken vimentin RNA and the decline in mammalian vimentin RNA in differentiating MEL cells suggest that the two sequences respond to different regulatory signals and that this differential response is mediated by a difference in cis-acting regulatory sequences. The increased transcription of the chicken vimentin gene in these differentiating cells further suggests a conservation of positively acting factors that are capable of interacting with similarly conserved chicken vimentin regulatory elements. It appears that

TABLE 4. Transcription in nuclei isolated from Faprt ${ }^{-} 585^{-} \mathrm{S}$ and $M E L C V-26$ cells

\begin{tabular}{|c|c|c|c|c|c|c|}
\hline \multirow{3}{*}{ Cells } & \multicolumn{6}{|c|}{ Transcription level(s) in: } \\
\hline & \multicolumn{3}{|c|}{ Expt 1} & \multicolumn{3}{|c|}{ Expt 2} \\
\hline & $\begin{array}{c}\text { cpm }^{a} \\
\text { Undifferentiated } \\
\text { cell }\end{array}$ & $\begin{array}{c}\text { cpm }^{a} \\
\text { Differentiated } \\
\text { cell }\end{array}$ & $\begin{array}{c}\text { Differentiated/ } \\
\text { undifferentiated } \\
\text { cell ratio }\end{array}$ & $\begin{array}{c}\text { cpm }^{a} \\
\text { Undifferentiated } \\
\text { cell }\end{array}$ & $\begin{array}{c}\text { cpm }^{a} \\
\text { Differentiated }^{b} \\
\text { cell }\end{array}$ & $\begin{array}{l}\text { Differentiated/ } \\
\text { undifferentiated } \\
\text { cell ratio }\end{array}$ \\
\hline \multicolumn{7}{|l|}{ Faprt $^{-585^{-} \mathrm{S}}$} \\
\hline Mouse vimentin & 27 & 11 & 0.41 & 30 & 14 & 0.46 \\
\hline$\beta$-Globin & 6 & 30 & 5.0 & 14 & 49 & 3.5 \\
\hline Actin & $\mathrm{ND}^{c}$ & ND & ND & 22 & 51 & 2.3 \\
\hline \multicolumn{7}{|l|}{$M E L C V-26$} \\
\hline Chicken vimentin & 28 & 120 & 4.2 & $182 ; 176^{d}$ & $430 ; 468^{d}$ & $2.5^{e}$ \\
\hline$\beta$-Globin & 7 & 21 & 3.1 & $18 ; 16^{d}$ & $46 ; 46^{d}$ & $2.7^{e}$ \\
\hline Hamster APRT & 10 & 30 & 2.9 & 30 & 58 & 1.9 \\
\hline Actin & ND & ND & ND & 9 & 35 & 3.9 \\
\hline Mouse vimentin & 33 & 24 & $0.72^{f}$ & 50 & 44 & $0.87^{f}$ \\
\hline
\end{tabular}


transfected chicken vimentin sequences respond to these putative factors in a manner appropriate for chicken vimentin sequences in an erythropoietic environment. A similar situation, in which an apparent divergence of target gene sequences is juxtaposed with a functional conservation of trans-acting regulatory factors, has been described for the avian and mammalian lens crystallins $(43,44,72)$. Although mammalian genomes contain no $\delta$-crystallin genes, chicken $\delta$-crystallin genes are appropriately regulated in a lensspecific fashion when microinjected directly into murine cell nuclei (44) or expressed in transgenic mice (43). Hence, both chicken $\delta$-crystallin and vimentin genes are appropriately expressed in murine xenogeneic environments according to the specificity of the species from which the genes originated.

The divergence of vimentin gene expression in avian and mammalian erythropoiesis, as mediated by cis-acting sequences, contrasts with the mechanism of fetal recruitment of embryonic globin genes in simian primates $(12,42)$. In simian primates, modern $\gamma$-globin genes exhibit a fetal pattern of expression but are believed to have evolved from an ancestral proto- $\gamma$ gene which exhibited an embryonic pattern of expression (25). In most nonprimate mammals, the descendants of this proto- $\gamma$ gene have maintained an embryonic pattern of expression. By studying the behavior of cloned human $\gamma$-globin genes during embryogenesis of transgenic mice, Chada et al. (12) and Kollias et al. (42) have observed an embryonic, rather than a fetal, pattern of $\gamma$-globin gene expression. The results suggest that the fetal recruitment of embryonic globin genes in simian primates is due to a temporal change in the expression of trans-acting factors specific for $\gamma$-like globin genes rather than a divergence of cis-acting $\gamma$-globin regulatory elements $(12,42)$. Moreover, these results suggest that the trans-acting factors governing $\gamma$-like globin gene expression, as well as the sequences with which they interact, have been conserved from rodents to humans $(12,42)$.

It is formally possible that increased accumulation of chicken vimentin RNA in differentiating MEL cells is a manifestation of gene transfection. Exogenous vimentin genes may be released from appropriate regulation by virtue of their aberrant chromosomal locations (assumed to be random), the exclusion of regulatory sequences in the plasmid DNA constructs used for transfection, or the proximity of vector sequences. For example, transfected cloned $\alpha$ globin genes are expressed at inappropriately high levels in nonerythroid cells $(38,59,87)$ and also appear to be maximally expressed in both undifferentiated and differentiated MEL cells (17). In contrast, $\alpha$-globin genes introduced into MEL cells by chromosome-mediated transfer are appropriately regulated during differentiation $(17,19-21)$, suggesting that chromatin configuration and/or local chromosome position effects factors play a key role in the regulated expression of $\alpha$-globin gene expression. Several lines of evidence argue against these possibilities for transfected vimentin gene expression. First, transfected hamster vimentin genes were found to be appropriately regulated. Of three MEL cell lines expressing hamster vimentin genes, all exhibited significantly reduced levels of hamster vimentin RNA after DMSO-mediated differentiation. It is therefore unlikely that the observed patterns of chicken vimentin expression in differentiating MEL cells are due to the absence of regulatory influences particular to the murine vimentin chromosomal locus. Second, we also obtained one MEL cell line containing vimentin sequences transferred on a genomic $\lambda$ recombinant, $\lambda V 8(10)$, which contains the entire chicken vimentin gene plus 6-kb $5^{\prime}$-flanking and 5-kb $3^{\prime}$-flanking sequences. This cell line expressed an increased amount of chicken vimentin RNA subsequent to DMSO-induced differentiation, albeit at low levels (data not shown). We therefore believe that both vimentin plasmid constructs used in this study contain sufficient flanking sequences to confer appropriately regulated expression and that the differences observed are not due to artificial exclusion of regulatory elements or interference by cis-linked vector or APRT gene sequences. Rather, the increased accumulation of chicken vimentin RNA and decreased accumulation of hamster vimentin RNA in differentiating MEL cells accurately reflect the phylogenetic class-specific differences of the transfected gene sequences. Finally, our results from in vitro nuclear run-on transcription experiments suggest that the differences in murine and chicken vimentin RNA accumulation in differentiating MEL cells are mediated in part by posttranscriptional mechanisms (see below for further discussion) which are independent of the above-mentioned transcriptional effects.

Nondiscriminatory utilization of chicken vimentin polyadenylation signals in MEL cells. The tissue-specific and developmentally regulated utilization of chicken vimentin RNA 3' termini suggests an important, albeit unknown, biological role for the differential expression of vimentin $3^{\prime}$ noncoding sequences (10). We therefore examined the patterns of chicken vimentin transcript polyadenylation in transfected MEL cell lines to detemine whether the mechanisms responsible for the differential utilization of vimentin polyadenylation sites in chicken definitive erythroid cells have been conserved in mammalian erythropoietic cells. The data of Fig. 4 demonstrate that the chicken vimentin $3^{\prime}$ termini are not utilized in a pattern distinctive of chicken definitive erythroid cells. It is possible that our DNA construct used for transfections lacked sufficient DNA sequence information to confer erythroid cell-specific transcript cleavage and polyadenylation. However, all three chicken vimentin $3^{\prime}$ termini were generated at the appropriate sites, indicating that sufficient downstream sequences indeed were present to direct proper transcript cleavage and polyadenylation (reviewed in reference 4). Our data suggest that, although the factors responsible for chicken vimentin gene activation have been functionally conserved in avian and mammalian erythropoiesis, the mechanism by which the chicken erythroid cell-specific pattern of polyadenylation site utilization occurs has diverged.

The role of transcriptional and posttranscriptional mechanisms in the regulation of vimentin mRNA levels in differentiating MEL cells. We performed in vitro nuclear run-on transcription experiments to determine the contribution of altered vimentin gene transcription rates to the changes in both endogenous and transfected vimentin mRNA steadystate levels. In two untransfected MEL cell lines, we found that transcription of the mouse vimentin gene reproducibly decreased to $\sim 40 \%$ of control levels after $96 \mathrm{~h}$ of DMSOmediated differentiation. This $\sim 2$-fold reduction in vimentin transcription in vitro contrasts with a corresponding 25 -fold decrease in steady-state vimentin mRNA (69; this paper). The apparent quantitative disparity in changes of vimentin transcription rates and steady-state vimentin mRNA levels suggests that the decline in murine vimentin mRNA in differentiating MEL cells is due in part to posttranscriptional mechanisms. However, vimentin gene transcription in isolated nuclei may not accurately reflect the quantitative changes in transcription in vivo. Although it is widely assumed that reinitiation does not occur in these transcrip- 
tion reactions (e.g., see reference 37), an overestimate of vimentin gene transcription during MEL cell differentiation could have been obtained. For example, the repression might be mediated by the induction of a labile or diffusible transcription factor whose activity is lost during the purification of nuclei. It should be noted, however, that the disparity in the rate of transcriptional decrease in vitro $(56 \%$ of control levels at $24 \mathrm{~h}, \sim 40 \%$ at $48 \mathrm{~h}$, and $\sim 40 \%$ at $96 \mathrm{~h}$ ) and the rate of steady-state mRNA level decrease $(30 \%$ of control levels at $24 \mathrm{~h}, 10 \%$ at $48 \mathrm{~h}$, and $4 \%$ at $96 \mathrm{~h}$ ) argues against such a possibility. Nevertheless, direct in vivo measurements of vimentin gene transcription rates and RNA decay kinetics will be necessary to quantitate the absolute contributions of transcriptional and posttranscriptional regulation to the decline in steady-state vimentin mRNA levels in differentiating MEL cells. Indeed, a combination of changes in transcription rate and posttranscriptional RNA processing, resulting in an overall greater change in mRNA steady-state levels, has been demonstrated for the cell cycle regulation of cellular thymidine kinase $(49,61,85)$ and histone (81) mRNAs, as well as for the induction of hormonally responsive $\operatorname{RNAs}(9,71,78)$. Transcriptional $(27,79)$ and posttranscriptional $(50)$ mechanisms also mediate the cell cycle regulation of dihydrofolate reductase mRNA levels.

A comparison of chicken and mouse vimentin gene transcription rates with the corresponding steady-state mRNA levels in differentiating MEL cells suggests that the divergent expression of these two genes in avian and mammalian erythropoiesis is effected at both the transcriptional and posttranscriptional levels. The increase in chicken vimentin RNA levels during differentiation of one transfected cell line, $M E L C V-26$, apparently is due to an increase in the rate of transcription as the increase in steady-state chicken RNA levels approximated the increase in transcription. The data suggest that mammalian vimentin cis-acting sequences have diverged from chicken sequences in such a way as to respond to both transcriptional repression (or deactivation) and differentiation-induced RNA destabilization.

Expression and persistence of filamentous chicken vimentin in differentiating MEL cells. Our studies show that differentiating MEL cells expressing chicken vimentin RNA accumulate vimentin filaments in the absence of endogenous mouse vimentin expression. Inappropriate expression of stable intermediate filaments in cultured cells by DNA transfection or microinjection of mRNA has been reported for the keratins and for desmin $(32,46,74)$. Together, these results suggest that intermediate filament proteins can polymerize in vivo in the absence of accessory proteins; however, the presence of heterologous intermediate filamentassociated proteins has not been ruled out in any of these cases.

We presume that chicken and mouse vimentins copolymerize when they are coexpressed in undifferentiated cells; although our antibodies react with both chicken and mouse vimentin and hence are not capable of discriminating between the two molecules by immunofluorescence microscopy, copolymerization of vimentin and desmin, vimentin and glial fibrillary acidic protein, and vimentin and neurofilament protein has been described $(35,75,76,82,83)$. As chicken vimentin-expressing MEL cells differentiate, the composition of intermediate filaments probably changes gradually from a mouse-chicken vimentin heteropolymer to a chicken vimentin homopolymer. Accumulation of chicken vimentin filaments in differentiating MEL cells argues against the possibility that endogenous murine vimentin filaments are normally removed from the cytoplasm by accelerated protein turnover, for example, by activation of a $\mathrm{Ca}^{2+}$-dependent vimentin-specific protease $(66,67)$ in response to an influx of $\mathrm{Ca}^{2+}$ ions $(15,48)$. The functionally conserved specificity of the vimentin-desmin-specific $\mathrm{Ca}^{2+}$. activated protease from fish to humans (68) suggests that if such an activity were activated in differentiating MEL cells, chicken vimentin also would be degraded. Since a MEL cell line that expresses low levels of chicken vimentin during differentiation also accumulates filaments in the absence of endogenous murine vimentin (data not shown), we believe that the accumulation of filaments is not due to an excess of protease substrate. Our results support a previous contention that the accumulation of vimentin filaments is determined primarily by the levels of newly synthesized vimentin $(5,62)$, which in turn are regulated at the level of mRNA abundance $(10,69)$.

Experimentally induced expression of vimentin filaments in MEL cells had no obvious effects on MEL cell differentiation. In the MEL cell lines described here, $\beta$-globin mRNA levels accumulated normally and cells exhibited patterns of growth kinetics and reductions in cell volume typical of MEL cell differentiation (data not shown; 55). We have speculated previously that removal of vimentin filaments in mammalian erythropoiesis facilitates the enucleation process (69). The experiments described here do not address this issue, since enucleation occurs subsequent to the period of MEL cell differentiation studied and, furthermore, maintenance of differentiating MEL cells to the anucleate reticulocytic stage is inherently problematical (90).

\section{ACKNOWLEDGMENTS}

We thank T. Enoch and T. Maniatis (Harvard University, Cambridge, Mass.) for their gift of pSP64- $\gamma$-actin, L. Brunet (University of California at Los Angeles) for helpful suggestions on in vitro nuclear transcription experiments, and Z. Zehner (Medical College of Virginia, Richmond) for graciously providing chicken vimentin gene sequence data prior to their publication.

This work was supported by a Public Health Service grant to E.L. from the National Institute on Aging. J.N. was supported by a Gordon Ross Medical Foundation predoctoral fellowship, and V.C.B. was supported by a National Institutes of Health postdoctoral fellowship.

\section{LITERATURE CITED}

1. Alter, B. P., and S. C. Goff. 1978. Variable globin chain synthesis in mouse erythroleukemia cells. Blood 52:1047-1057.

2. Aviv, H., and P. Leder. 1972. Purification of biologically active globin mRNA by chromatography on oligothymidylic acidcellulose. Proc. Natl. Acad. Sci. USA 69:1408-1412.

3. Axelfod, V. D., and F. R. Kramer. 1985. Transcription from bacteriophage T7 and SP6 RNA polymerase promoters in the presence of $3^{\prime}$ deoxyribonucleoside $5^{\prime}$ triphosphate chain terminators. Biochemistry 24:5716-5723.

4. Birnstiel, M. L., M. Busslinger, and K. Strub. 1985. Transcription termination and $3^{\prime}$ processing: the end is in site! Cell 41:349-359.

5. Blikstad, I., and E. Lazarides. 1983. Vimentin filaments are assembled from a soluble precursor in avian erythroid cells. J. Cell Biol. 96:1803-1808.

6. Bond, V. C., and B. Wold. 1987. Poly-L-ornithine-mediated transformation of mammalian cells. Mol. Cell. Biol. 7:22862293.

7. Bouves, W. M., and R. A. Laskey. 1974. A film detection method for tritium-labeled proteins and nucleic acids in polyacrylamide gels. Eur. J. Biochem. 46:83-88.

8. Bradley, R. H., M. Ireland, and H. Maisel. 1979. The cytoskeleton of chick lens cells. Exp. Eye Res. 28:441-453. 
9. Brock, M. L., and D. J. Shapiro. 1983. Estrogen stabilizes vitellogenin mRNA against cytoplasmic degradation. Cell 34:207-214.

10. Capetanaki, Y. G., J. Ngai, C. N. Flytzanis, and E. Lazarides. 1983. Tissue-specific expression of two mRNA species transcribed from a single vimentin gene. Cell 35:411-420.

11. Carey, M. F., K. Singh, M. Botchan, and N. R. Cozzarelli. 1986. Induction of specific transcription by RNA polymerase III in transformed cells. Mol. Cell. Biol. 6:3068-3076.

12. Chada, K., J. Magram, and F. Costantini. 1986. An embryonic pattern of expression of a human fetal globin gene in transgenic mice. Nature (London) 319:685-689.

13. Chao, M. V. 1986. Expression of transfected genes, p. 223-241. In R. Kucherlapati (ed.), Gene transfer. Plenum Publishing Corp., New York.

14. Chao, M. V., P. Mellon, P. Charnay, T. Maniatis, and R. Axel. 1983. The regulated expression of $\beta$-globin genes introduced into mouse erythroleukemia cells. Cell 32:483-493.

15. Chapman, L. F. 1980. Effect of calcium on differentiation of Friend leukemia cells. Dev. Biol. 79:243-246.

16. Charnay, P., P. Mellon, and T. Maniatis. 1985. Linker scanning mutagenesis of the 5 -flanking region of the mouse $\beta$-majorglobin gene: sequence requirements for transcription in erythroid and nonerythroid cells. Mol. Cell. Biol. 5:1498-1511.

17. Charnay, P., R. Treisman, P. Mellon, M. Chao, R. Axel, and T. Maniatis. 1984. Differences in human $\alpha$ - and $\beta$-globin gene expression in mouse erythroleukemia cells: the role of intragenic sequences. Cell 38:251-263.

18. Chirgwin, J. M., A. E. Przybyla, R. J. MacDonald, and W. J. Rutter. 1979. Isolation of biologically active ribonucleic acid from sources enriched in ribonuclease. Biochemistry 18:52945299.

19. Deisseroth, A., U. Bode, J. Fontana, and D. Hendrick. 1980. Expression of human $\alpha$-globin genes in hybrid mouse erythroleukemia cells depends on differentiated state of human donor cell. Nature (London) 285:36-38.

20. Deisseroth, A., and D. Hendrick. 1978. Human $\alpha$-globin gene expression following chromosomal dependent gene transfer into mouse erythroleukemia cells. Cell 15:55-63.

21. Deisseroth, A., and D. Hendrick. 1979. Activation of phenotypic expression of human globin genes from nonerythroid cells by chromosome-dependent transfer to tetraploid mouse erythroleukemia cells. Proc. Natl. Acad. Sci. USA 76:2185-2189.

22. Dellagi, K., W. Vainchenker, G. Vinci, D. Paulin, and J: C. Brouet. 1983. Alteration of vimentin intermediate filament expression during differentiation of human hemopoietic cells. EMBO J. 2:1509-1514.

23. Dodemont, H. J., P. Soriano, W. J. Quax, F. Ramaekers, J. A. Lenstra, M. A. M. Groenen, G. Bernardi, and H. Bloemendal. 1982. The genes coding for the cytoskeletal proteins actin and vimentin in warm-blooded vertebrates. EMBO J. 1:167-171.

24. Dräger, U. C. 1983. Coexistence of neurofilaments and vimentin in a neurone of adult mouse retina. Nature (London) 303:169172 .

25. Efstratiadis, A., J. W. Posakony, T. Maniatis, R. M. Lawn, C. O'Connell, R. A. Spritz, J. K. De Riel, B. G. Forget, S. M. Weissman, J. L. Slightom, A. E. Blechl, O. Smithies, F. E. Baralle, C. C. Shoulders, and N. J. Proudfoot. 1980. The structure and evolution of the human $\beta$-globin gene family. Cell 21:653-668.

26. Enoch, T., K. Zinn, and T. Maniatis. 1986. Activation of the human $\beta$-interferon gene requires an interferon-inducible factor. Mol. Cell. Biol. 6:801-810.

27. Farnam, P. J., and R. Schimke. 1985. Transcriptional regulation of mouse dihydrofolate reductase in the cell cycle. J. Biol. Chem. 260:7675-7680.

28. Ferrari, S., R. Battini, L. Kaczmarek, S. Rittling, B. Calabretta, J. K. de Riel, V. Philiponis, J.-F. Wei, and R. Baserga. 1986. Coding sequence and growth regulation of the human vimentin gene. Mol. Cell. Biol. 6:3614-3620.

29. Franke, W. W., E. Schmid, M. Osborn, and K. Weber. 1978. Different intermediate-sized filaments distinguished by immunofluorescence microscopy. Proc. Natl. Acad. Sci. USA 75:5034-
5038.

30. Friend, C., W. Scher, J. G. Holland, and T. Sato. 1971. Hemoglobin synthesis in murine virus-induced leukemic cells in vitro: stimulation of erythroid differentiation by dimethyl sulfoxide. Proc. Natl. Acad. Sci. USA 68:378-382.

31. Gard, D. L., P. B. Bell, and E. Lazarides. 1979. Coexistence of desmin and the fibroblastic intermediate filament subunit in muscle and non-muscle cells: identification and comparative peptide analysis. Proc. Natl. Acad. Sci. USA 76:3894-3898.

32. Giudice, G. J., and E. Fuchs. 1987. The transfection of epidermal keratin genes into fibroblasts and single epithelial cells: evidence for inducing a type I keratin by a type II gene. Cell 48:453-463.

33. Granger, B. L., and E. Lazarides. 1979. Desmin and vimentin coexist at the periphery of the myofibril $\mathrm{Z}$ disc. Cell 18:10531063.

34. Granger, B. L., and E. Lazarides. 1982. Structural associations of synemin and vimentin filaments in avian erythrocytes revealed by immunoelectron microscopy. Cell 30:263-275.

35. Granger, B. L., and E. Lazarides. 1983. Expression of the major neurofilament subunit in chicken erythrocytes. Science 221: 553-556.

36. Granger, B. L., E. A. Repasky, and E. Lazarides. 1982. Synemin and vimentin are components of intermediate filaments in avian erythrocytes. J. Cell Biol. 92:299-312.

37. Groudine, M., M. Peretz, and H. Weintraub. 1981. Transcriptional regulation of hemoglobin switching in chicken embryos. Mol. Cell. Biol. 1:281-288.

38. Humphries, R. K., T. Ley, P. Turner, A. D. Moulton, and A. W. Nienhuis. 1982. Differences in human $\alpha-, \beta$ - and $\delta$-globin gene expression in monkey kidney cells. Cell 30:173-183.

39. Jones, K. A., K. R. Yamamoto, and R. Tjian. 1985. Two distinct transcription factors bind to the HSV thymidine kinase promoter in vitro. Cell 42:559-572.

40. Kafatos, F. C., C. W. Jones, and A. Efstratiadis. 1979. Determination of nucleic acid sequence homologies and relative concentrations by a dot hybridization procedure. Nucleic Acids Res. 7:1541-1552.

41. Kedinger, C., M. Gniazdowski, J. L. Mandel, F. Gissinger, Jr., and P. Chambon. 1970. $\alpha$-Amanitin: a specific inhibitor of one of two DNA-dependent RNA polymerase activities from calf thymus. Biochem. Biophys. Res. Commun. 38:165-171.

42. Kollias, G., N. Wrighton, J. Hurst, and F. Grosveld. 1986. Regulated expression of human ${ }^{A} \gamma-, \beta-$, and hybrid $\gamma \beta$-globin genes in transgenic mice: manipulation of the developmental expression patterns. Cell 46:89-94.

43. Kondoh, H., K. Katoh, Y. Takahashi, H. Fujisawa, M. Yokoyama, S. Kimura, M. Katsuki, M. Saito, T. Nomura, Y. Hiramoto, and T. S. Okada. 1987. Specific expression of the chicken $\delta$-crystallin gene in the lens and the pyramidal neurons of the piriform cortex of transgenic mice. Dev. Biol. 120:177185.

44. Kondoh, H., K. Yasuda, and T. S. Okada. 1983. Tissue-specific expression of a cloned chick $\delta$-crystallin gene in mouse cells: Nature (London) 301:440-442.

45. Konkel, D. A., J. V. Maizel, and P. Leder. 1979. The evolution and sequence comparison of two recently diverged mouse chromosomal $\beta$-globin genes. Cell 18:865-873.

46. Kreis, T. E., B. Geiger, E. Schmid, J. L. Jorcano, and W. W. Franke. 1983. De novo synthesis and specific assembly of keratin filaments in non-epithelial cells after microinjection of mRNA for epidermal keratin. Cell 32:1125-1137.

47. Lazarides, E. 1982. Intermediate filaments: a chemically heterogeneous, developmentally regulated class of proteins. Annu. Rev. Biochem. 51:219-250.

48. Levenson, R., D. Houseman, and L. Cantley. 1980. Amiloride inhibits murine erythroleukemia cell differentiation: evidence for a $\mathrm{Ca}^{2+}$ requirement for commitment. Proc. Natl. Acad. Sci. USA 77:5948-5952.

49. Lewis, J. A., and D. A. Matkovich. 1986. Genetic determinants of growth phase-dependent and adenovirus 5-responsive expression of the Chinese hamster thymidine kinase gene are contained within thymidine kinase mRNA sequences. Mol. 
Cell. Biol. 6:2262-2266.

50. Leys, E. J., G. F. Crouse, and R. E. Kellems. 1984. Dihydrofolate reductase gene expression in cultured mouse cells is regulated by transcript stabilization in the nucleus. J. Cell Biol. 99:180-187.

51. Lindell, T. J., F. Weinberg, P. W. Morris, R. G. Roeder, and W. J. Rutter. 1970. Specific inhibition of nuclear RNA polymerase II by $\alpha$-amanitin. Science 170:447-449.

52. Linial, M., N. Gunderson, and M. Groudine. 1985. Enhanced transcription of c-myc in bursal lymphoma cells requires continuous protein synthesis. Science 230:1126-1132.

53. Lowy, I., A. Pellicer, J. F. Jackson, G.-K. Sim, S. Silverstein, and R. Axel. 1980. Isolation of transforming DNA: cloning the hamster aprt gene. Cell 22:817-823.

54. Maniatis, T., E. F. Fritsch, and J. Sambrook. 1982. Molecular cloning: a laboratory manual. Cold Spring Harbor Laboratory, Cold Spring Harbor, N.Y.

55. Marks, P. A., and R. A. Rifkind. 1978. Erythroleukemic differentiation. Annu. Rev. Biochem. 47:419-448.

56. Maxam, A. M., and W. Gilbert. 1980. Sequencing end-labeled DNA with base-specific chemical cleavages. Methods Enzymol. 65:499-560.

57. McKnight, G. S., and R. D. Palmiter. 1979. Transcriptional regulation of the ovalbumin and conalbumin genes by steroid hormones in chick oviduct. J. Biol. Chem. 254:9050-9058.

58. McTavish, C. F., W. J. Nelson, and P. Traub. 1983. Synthesis of vimentin in a reticulocyte cell-free system programmed by poly(A)-rich RNA from several cell lines and rat liver. Eur. J. Biochem. 130:211-221.

59. Mellon, P., V. Parker, Y. Gluzman, and T. Maniatis. 1981. Identification of DNA sequences required for transcription of the human $\alpha$-1-globin gene in a new SV40 host-vector system. Cell 27:279-288.

60. Melton, D. A., P. A. Krieg, M. R. Rebagliati, T. Maniatis, K. Zinn, and M. R. Green. 1984. Efficient in vitro synthesis of biologically active RNA and RNA hybridization probes from plasmids containing bacteriophage SP6 promoter. Nucleic Acids Res. 12:7035-7056.

61. Merrill, G. F., S. D. Hauschka, and S. L. McKnight, 1984. tk enzyme expression in differentiating muscle cells is regulated through an internal segment of the cellular $t k$ gene. Mol. Cell. Biol. 4:1777-1784.

62. Moon, R. T., and E. Lazarides. 1983. Synthesis and posttranslational assembly of intermediate filaments in avian erythroid cells: vimentin assembly limits the rate of synemin assembly. Proc. Natl. Acad. Sci. USA 80:5495-5499.

63. Moon, R. T., J. Ngai, B. J. Wold, and E. Lazarides. 1985 Tissue-specific expression of distinct spectrin and ankyrin transcripts in erythroid and nonerythroid cells. J. Cell Biol. 100:152-160.

64. Nalbantoglu, J., G. A. Phear, and M. Meuth. 1986. Nucleotide sequence of hamster adenine phosphoribosyl transferase (aprt) gene. Nucleic Acids Res. 14:1914.

65. Nalbantoglu, J., G. Phear, and M. Meuth. 1987. DNA sequence analysis of spontaneous mutations at the aprt locus of hamster cells. Mol. Cell. Biol. 7:1445-1449.

66. Nelson, W. J., and P. Traub. 1981. Properties of a Ca ${ }^{+}$-activated protease specific for the intermediate-sized filament protein vimentin in Ehrlich-ascites-tumor cells. Eur. J. Biochem. 16:51-57.

67. Nelson, W. J., and P. Traub. 1982. Purification and further characterization of the $\mathrm{Ca}^{2+}$-activated proteinase specific for the intermediate filament proteins vimentin and desmin. J. Biol. Chem. 257:5544-5553.

68. Nelson, W. J., and P. Traub. 1982. Intermediate $(10 \mathrm{~nm})$ filament proteins and the $\mathrm{Ca}^{2+}$-activated proteinase specific for vimentin and desmin in the cells from fish to man: an example of evolutionary conservation. J. Cell Sci. 57:25-49.

69. Ngai, J., Y. G. Capetanaki, and E. Lazarides. 1984. Differentiation of murine erythroleukemia cells results in the rapid repression of vimentin gene expression. J. Cell Biol. 99:306-314.

70. O'Farrell, P. H. 1975. High resolution two-dimensional electrophoresis of proteins. J. Biol. Chem. 250:4007-4021.
71. Paek, I., and R. Axel. 1987. Glucocorticoids enhance stability of human growth hormone mRNA. Mol. Cell. Biol. 7:1496-1507.

72. Piatigorsky, J. 1984. Lens crystallins and their gene families. Cell 38:620-621.

73. Quax, W., W. V. Egberts, W. Hendriks, Y. Quax-Jeuken, and H. Bloemendal. 1983. The structure of the vimentin gene. Cell 35:215-223.

74. Quax, W., L. van der Broek, W. V. Egberts, F. Ramaekers, and H. Bloemendal. 1985. Characterization of the hamster desmin gene: expression and formation of desmin filaments in nonmuscle cells after gene transfer. Cell 43:327-338.

75. Quinlan, R. A., and W. W. Franke. 1982. Heteropolymer filaments of vimentin and desmin in vascular smooth muscle tissue and cultured baby hamster kidney cells demonstrated by chemical crosslinking. Proc. Natl. Acad. Sci. USA 79:3452-3456.

76. Quinlan, R. A., and W. W., Franke. 1983. Molecular interactions in intermediate-sized filaments revealed by chemical cross-linking. Heteropolymers of vimentin and glial filament protein in cultured human glioma cells. Eur. J. Biochem. 132:477-484.

77. Ramaekers, F. C. S., M. Osborn, E. Schmid, K. Weber, H. Bloemendal, and W. W. Franke. 1980. Identification of the cytoskeletal proteins in lens-forming cells, a special epithelioid cell type. Exp. Cell Res. 127:309-327.

78. Robins, D. M., I. Paek, P. H. Seeburg, and R. Axel. 1982. Regulated expression of human growth hormone genes in mouse cells. Cell 29:623-631.

79. Santiago, C., M. Collins, and L. F. Johnson. 1984. In vitro and in vivo analysis of the control of dihydrofolate reductase gene transcription in serum-stimulated mouse fibroblasts. J. Cell. Physiol. 118:79-86.

80. Schnitzer, J., W. W. Franke, and M. Schachner. 1981. Immunocytochemical demonstration of vimentin in astrocytes and ependymal cells of developing and adult mouse nervous system. J. Cell Biol. 90:435-447.

81. Schümperli, D. 1986. Cell cycle regulation of histone gene expression. Cell 45:471-472.

82. Sharp, G., M. Osborn, and K. Weber. 1982. Occurrence of two different intermediate filament proteins in the same filament in situ within a human glioma cell line. Exp. Cell Res. 141:385-395.

83. Steinert, P. M., W. W. Idler, F. Cabral, M. M. Gottesman, and R. D. Goldman. 1981. In vitro assembly of homopolymer and copolymer filaments from intermediate filament subunits of muscle and fibroblastic cells. Proc. Natl. Acad. Sci. USA 78: 3692-3696.

84. Steinert, P. M., A. C. Steven, and D. R. Roop. 1985. The molecular biology of intermediate filaments. Cell 42:411-419.

85. Stewart, C. J., M. Ito, and S. E. Conrad. 1987. Evidence for transcriptional and post-transcriptional control of the cellular thymidine kinase gene. Mol. Cell. Biol. 7:1156-1163.

86. Tapscott, S. J., G. S. Bennett, Y. Toyama, F. Kleinbart, and H. Holtzer. 1981. Intermediate filament proteins in the developing chick spinal cord. Dev. Biol. 86:40-54.

87. Treisman, R., M. R. Green, and T. Maniatis. 1983. cis- and trans-activation of globin gene transcription in transient assays. Proc. Natl. Acad. Sci. USA 80:7428-7432.

88. Tuszynski, G. P., E. D. Frank, C. H. Damsky, C. A. Buck, and L. Warren. 1979. The detection of smooth muscle desmin-like protein in $\mathrm{BHK}_{21} / \mathrm{C}_{13}$ fibroblasts. J. Biol. Chem. 254:6138-6143.

89. Virtanen, I., M. Kurkinen, and V.-P. Lehto. 1979. Nucleusanchoring cytoskeleton in chicken red blood cells. Cell Biol. Int. Rep. 3:157-162.

90. Volloch, V., and D. Houseman. 1982. Terminal differentiation of murine erythroleukemia cells: physical stabilization of end stage cells. J. Cell Biol. 93:390-394.

91. Wigler, M., R. Sweet, G. K. Sim, B. Wold, A. Pellicer, E. Lacy, T. Maniatis, S. Silverstein, and R. Axel. 1979. Transformation of mammalian cells with genes from procaryotes and eucaryotes. Cell 16:777-785.

92. Woodcock, C. L. F. 1980. Nucleus-associated intermediate filaments from chicken erythrocytes. J. Cell Biol. 85:881-889.

93. Wright, S., E. de Boer, F. G. Grosveld, and R. A. Flavell. 1983. Regulated expression of the human $\beta$-globin gene family in 
murine erythroleukemia cells. Nature (London) 305:333-336.

94. Wright, S., A. Rosenthal, R. Flavell, and F. Grosveld. 1984. DNA sequences required for regulated expression of $\beta$-globin genes in murine erythroleukemia cells. Cell 38:265-273.

95. Yen, S. H., and K. L. Fields. 1981. Antibodies to neurofilamént, glial filament, and fibroblast intermediate filament proteins bind to different cell types of the nervous system. J. Cell Biol. 88:115-126.

95a.Zehner, Z. E., Y. Li, B. A. Roe, B. M. Paterson, and C. M. Sax. 1987. The chicken vimentin gene: nucleotide sequence, regulatory elements, and comparison to the hamster gene. J. Biol.
Chem. 262:8112-8120.

96. Zehner, Z. E., and B. M. Paterson. 1983. Characterization of the chicken vimentin gene: single copy gene producing multiple mRNAs. Proc. Natl. Acad. Sci. USA 80:911-915.

97. Zehner, Z. E., and B. M. Pàterson. 1983. Vimentin gene expression during myogenesis: two functional transcripts from a single copy gene. Nucleic Acids Res. 11:8317-8332.

98. Zinn, K., D. DiMaio, and T. Maniatis. 1983. Identification of two distinct regulatory regions adjacent to the human $\beta$-interferon gene. Cell 34:865-879. 